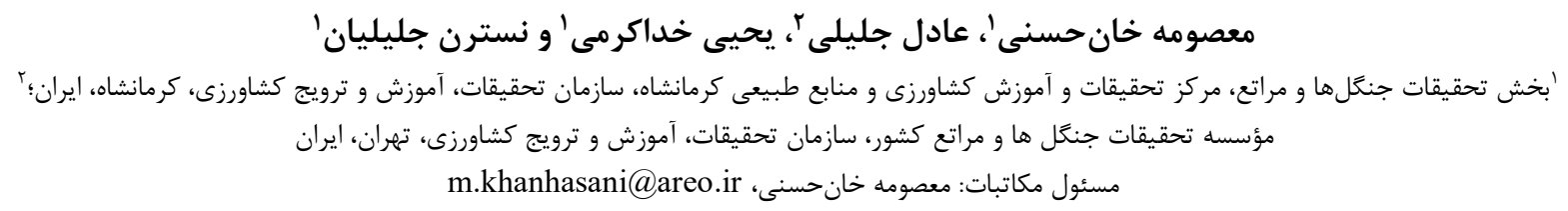

קكيده. يراكندگى رودخانهها، بركهها وجمنزارهاى كوخى و بزرگ، موقتى و دائمى، زمينه را براى ظهور رويشاههاى ماندابى خصوصا در مناطق كوهستانى كشور فراهم كرده

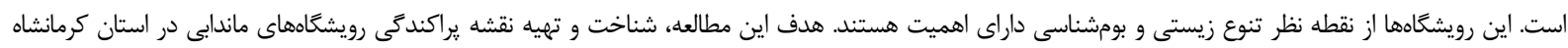

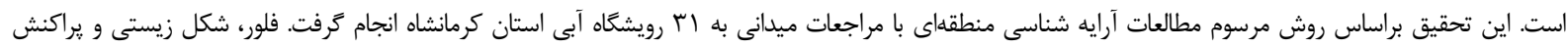

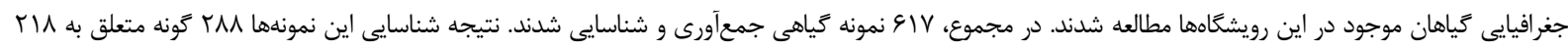

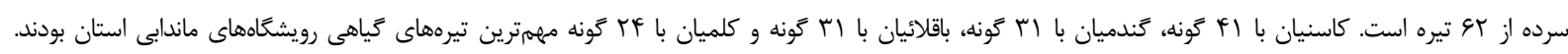

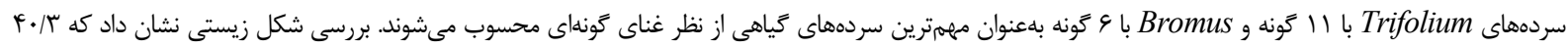

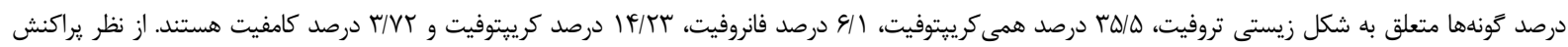

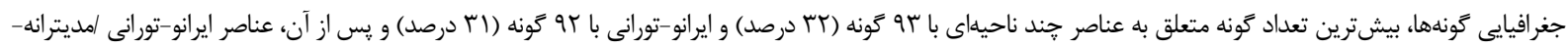

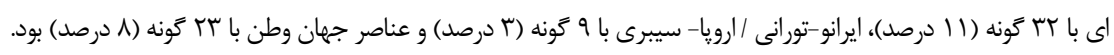
وازههاى كليدى. يراكنش جغرافيايى، تنوع زيستى، رويشكاههاى ماندابى، شكل زيستى، كياهان آبزى

\title{
Wetland flora of Kermanshah Province, Iran
}

\author{
Masoumeh Khanhasani ${ }^{1}$, Adel Jalili ${ }^{2}$, Yahya Khodakarami ${ }^{1}$ \& Nastaran Jalilian $^{1}$ \\ ${ }^{1}$ Forests and Rangelands Research Department, Kermanshah Agricultural and Natural Resources Research and \\ Education Center, AREEO, Kermanshah, Iran; ${ }^{2}$ Research Institute of Forests and Rangelands, Agricultural Research, \\ Education and Extension Organization (AREEO), Tehran, Iran \\ Corresponding author: Masoumeh Khanhasani, m.khanhasani@areeo.ir
}

\begin{abstract}
Distribution of rivers, pools and grasslands, being large or small and perennial or temporary, have created conditions suitable for the establishment of wetlands, especially in the highland regions of the Country. These habitats are highly important for the preservation of biodiversity and other ecological aspects. The present study aimed to identify wetlands in the Kermanshah Province, Iran, and map their distribution. The investigation was carried out on the basis of the conventional taxonomic studies of the region by doing field observation in 31 aqueous habitats in Kermanshah Province. The flora of each habitats and the life form and geographical distribution of the species were investigated. In total, 617 plant specimens, belonging to 288 species, 218 genera and 62 families, were collected identified and stored in the herbarium of the research center of agriculture and natural resources of Kermanshah Province (RANK). Asteraceae with 41 species, Poaceae with 31 species, Fabaceae with 31 species and Brassicaceae with 24 species were found to be the most important families of the wetlands studied. Trifolium with 11 species and Bromus with 6 species were the most important genera, in terms of species richness. Detection of the biological forms showed that $40.3 \%$ of the species were trophytes, $35 / 5 \%$ were hemicryptophyts, $6 / 1 \%$ were phanerophytes, $14 / 23 \%$ were cryptophytes and 3/72\% were chamaephytes. The chorology of species showed that 93 species belonged to more than two elements (32\%), 92 species $(31 \%)$ to the Irano-Touranin elements, 32 species to Irano-Touranin- Mediterranean (11\%), 9 species to Irano-TouraninEuro-Siberian with (3\%) and 23 species were found to be cosmopolitan elements ( $8 \%)$.
\end{abstract}

Key words. biodiversity, chorology, hydrophytes, life form, wetlands

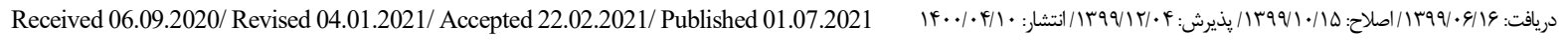


سالهاى اخير صورت گرفته است. نتيجه مطالعه فلور ماندابى

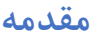

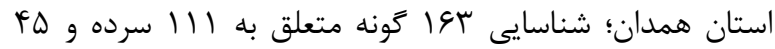
تيره گياهى است (Safikhani et al., 2018). مطالعه فلور تالاب

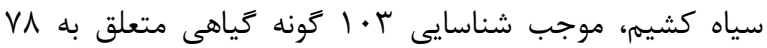

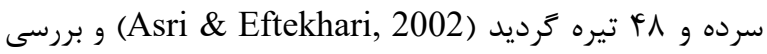

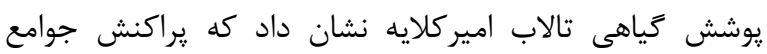

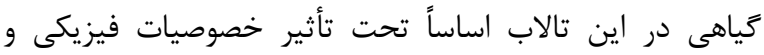
شيميايى آب قرار دارند (Asri \& Moradi, 2004). نتيجه مطالعه يوشش كياهى در شبه جزيره ميانكاله نيز نشان داد داد كه يراكنش جامعههاى گياهى اين منطقه تحت تأثير خصوصيات شيميايى خاك و سطح ايستايى قرار مى ئيرند (Asri et al., 2007)

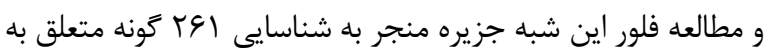

. 4 تيره و VVV اسرده گرديد (Sharifnia et al., 2007). از جمله مطالعات جلبكهاى آب شيرين مىتوان به بردئ كردي

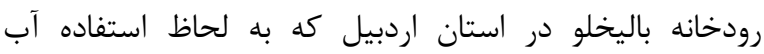

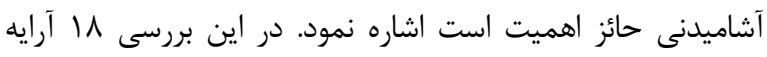

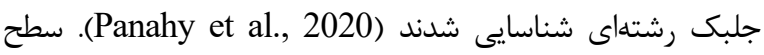
وسيعى از ايران تحت يوشش مناطق كوهستانى است. در اين مناطق شئق به علت وجود رودخانهها، جويبارها، جشمهسارهاى متعدد و يراكنده

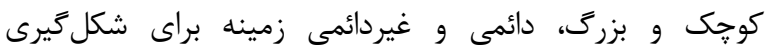

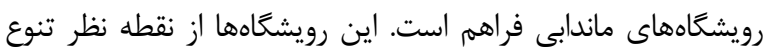

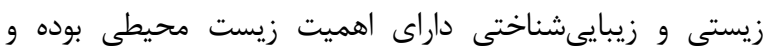
همجنين نقش حياتى در زندكى اقتصادى مردم دارند.

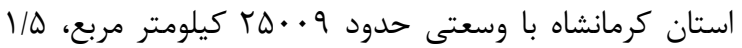

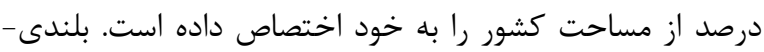
هاى زاگرس با داشتن كوههايى جون شاهو، يراو، امروله،

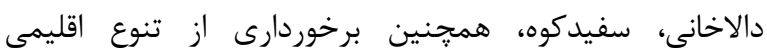

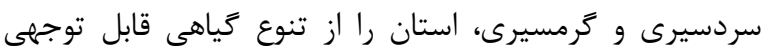
برخوردار نموده است. بيش از يكصد دهنه جشمه بز آز

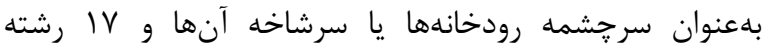

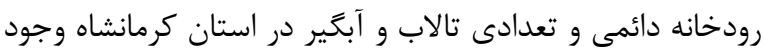
دارد (كزارش اداره كل حفاظت محيط زيست استان كرمانشاه).

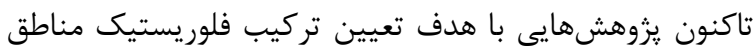

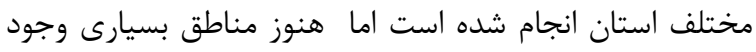

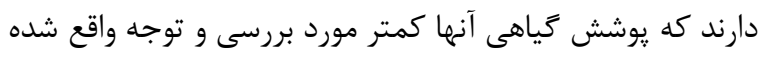

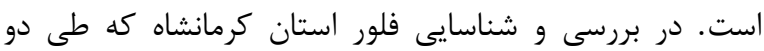

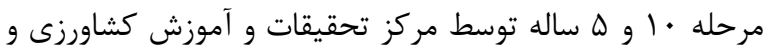

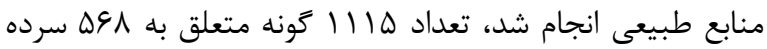
و كو تيره شناسايى شد (Jalilian et al., 2017). از آنجايى كه بدون شناخت بومساز كانها، بهرهكيرى مستمر از وازه تالاب معادل با Wetland به كار برده شده است اما هنوز بلهور كامل تعريف دقيقى كه هم جامع و هم بيانكر تمام

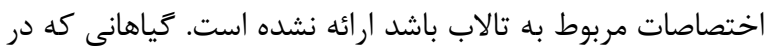
جنين اكوسيستمهايى رشد مى كنند به كياهان هيدروفيت موسوماند وكياهانى هستند كه با شرايط بومشناختى ويز آنداى

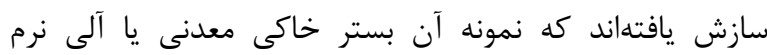

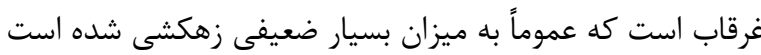

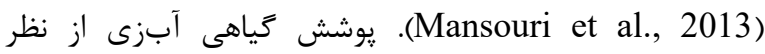

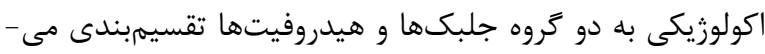

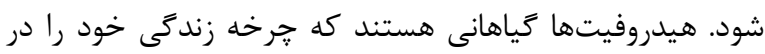
آب كامل مى كنند و بهطور مستقيم موجب خسارت به محيط خديط

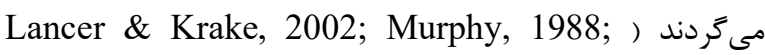
.(Pieterse \& Murphy, 1993

هيدروفيتها بافتهاى هادى و حفاظتى كمترى نسبت به

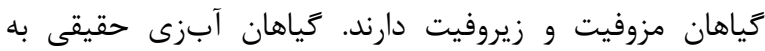

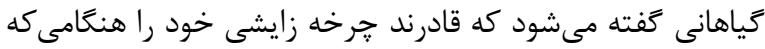

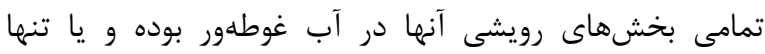

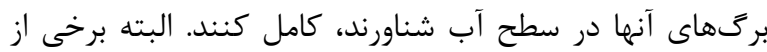
مؤلفين علاوهبر كياهان آبزى مزبور، كياهان آبزى دئ ديخرى كه

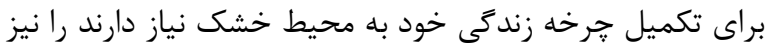

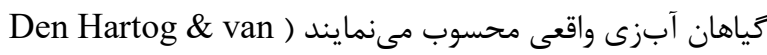
.(der Velde, 1988; Den Hartog \& Segal, 1964 در ايران مطالعه رويشكاههاى ماندابى معطوف به تالابها بوده

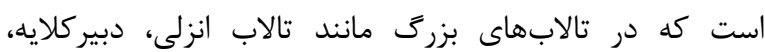

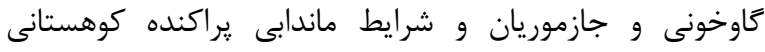
خصوصاً از نقطه نظر بومشناختى كمتر مورد توجه بوده است. در دران

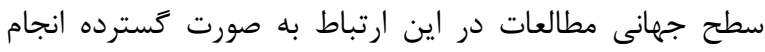
كرفته است. مطالعهاى جهت بررسى تغييرات كياهان بر اثر تغييرات

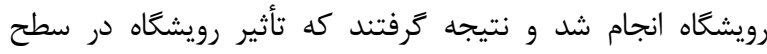
رستههاى كياهى مشهودتر از سطح تركيب كَونهاى است و اختلال در رويشكاه باعث كاهش رستنىهاى بومى و گَياهان علفى جندساله

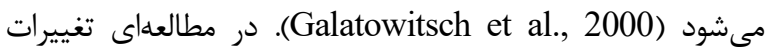

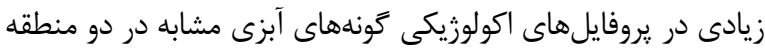

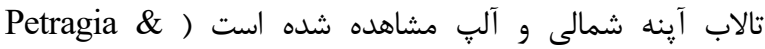

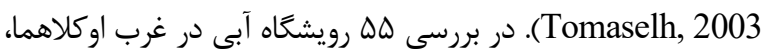
^ كروه كياهى معرفى شده كه .Typha domingensis Pers. Choenoplectus americanus (Pers.) Volkart بودند (Hogland, 2002). مطالعات متعددى مرتبط با فلور محيطهاى آبى ايران در 
ثبت گرديد. همزمان با مكانيابى تالاب، كليه گ گنههاى گياهى

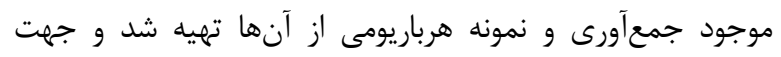

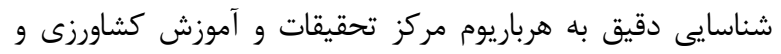

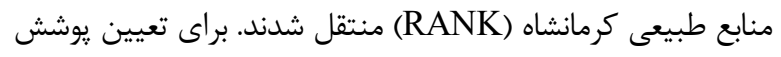

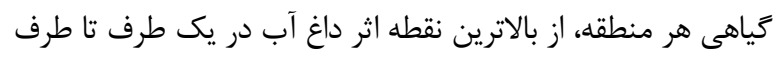
ديكر، يك خط مستقيم فرضى رسم كرده و در امتداد آن به تهرئ آنهيه

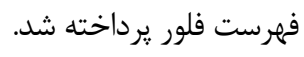
تالابها و سرابهاى متعددى در سطح استان مورد بازديد قرار

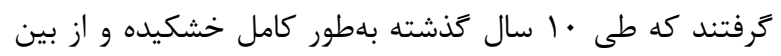

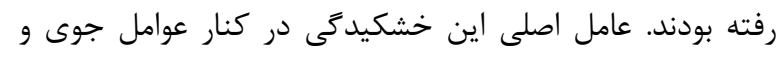

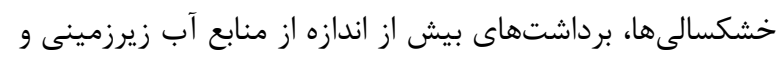

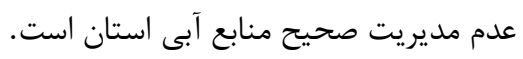

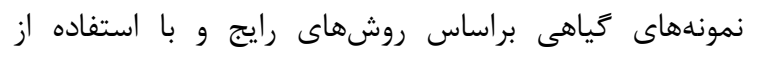

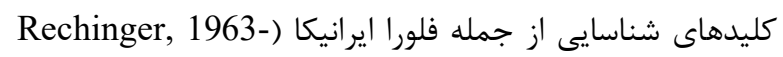

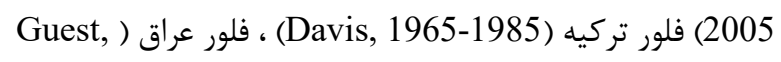

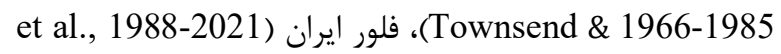
(Mobayen, 1980-1996) رستنىهاى ايران (19ssadi

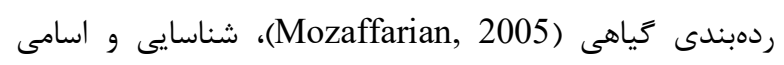
مؤلفان آرايهها با نمايه بين المللى نامهاى كياهى (IPNI, 2020)

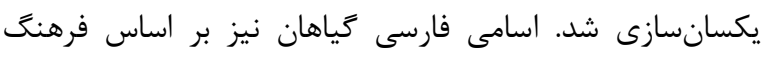
نامهاى كياهان ايران انجام ترفت (Mozaffarian, 1998). تيرهها و سردهاى فلور زيستخاههاى ماندابى با سيستم ردهبندى إنى APG IV (APG, 2016)

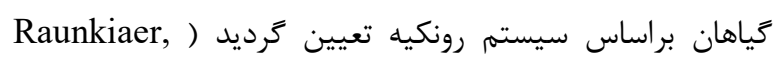
1934). اين سيستم طبقهبندى در تمامى شرايط محيطى روش رون

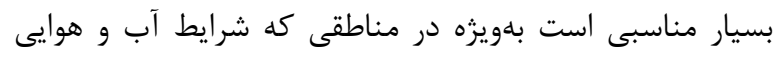

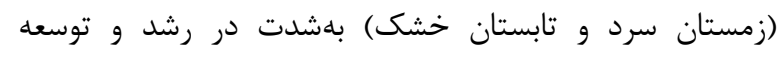

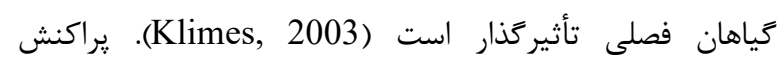

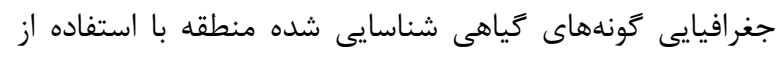

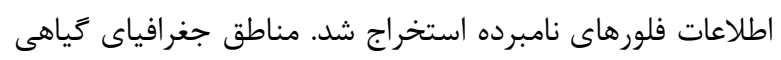

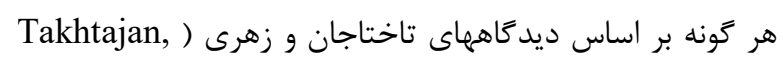
(1986; Zohary, 1973

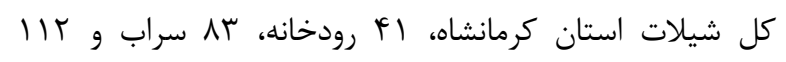

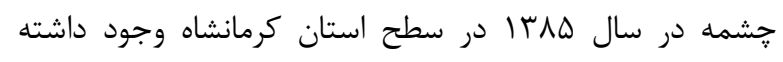

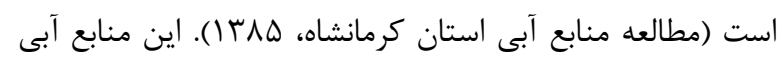

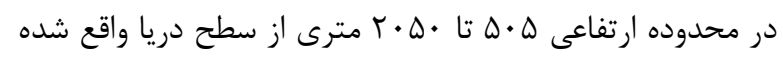

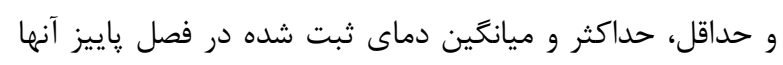

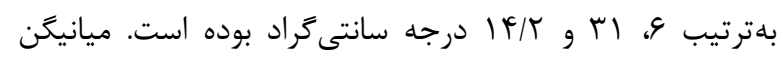

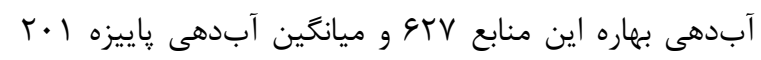

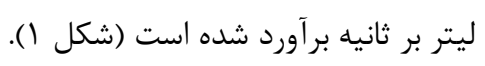

آنها ناممكن است بنابراين بررسى و شناخت آنها بهويزه بوم-

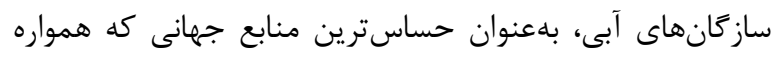

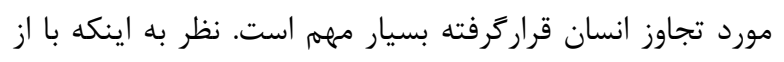

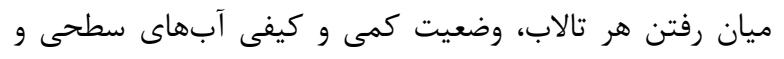

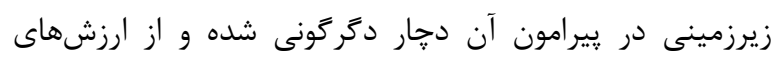

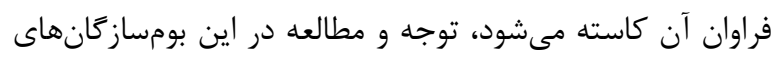

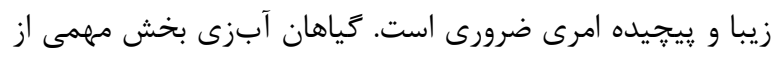

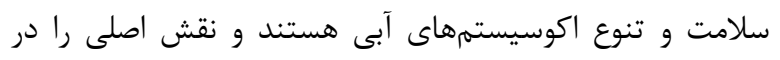

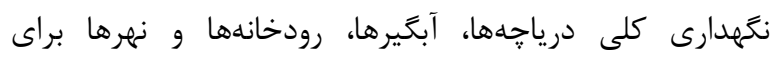

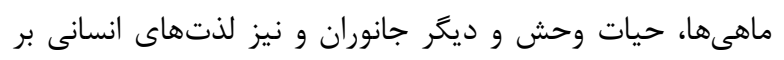

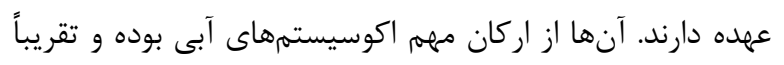

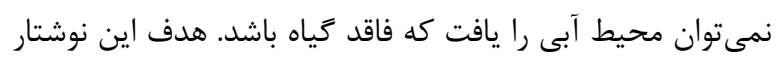

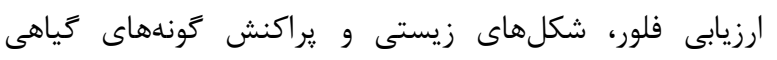
موجود در مهمترين رويشكاه هاى آبى استان كرمانشاه است.

$$
\text { مواد و روشها }
$$

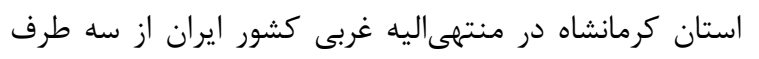

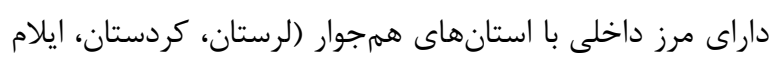

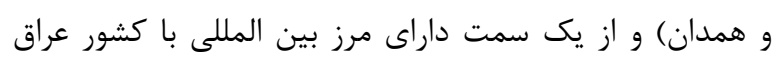

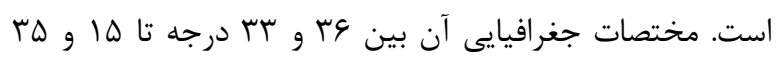

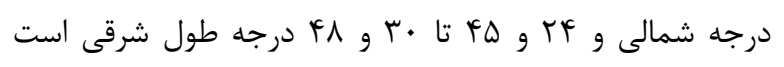

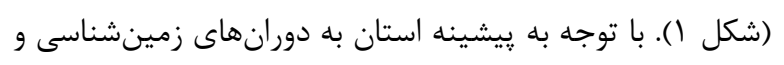

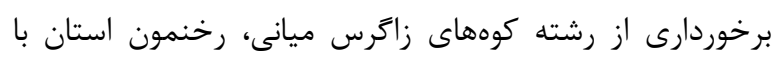

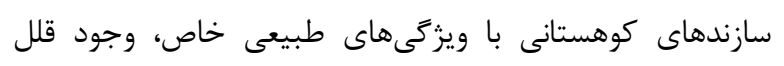

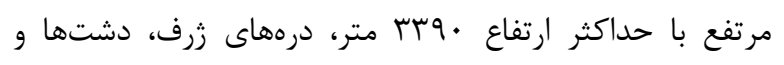

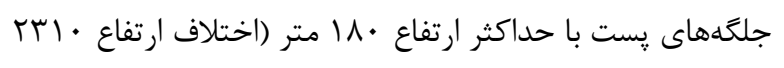

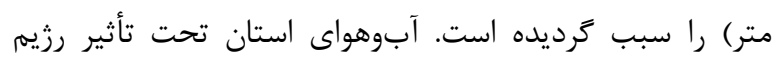

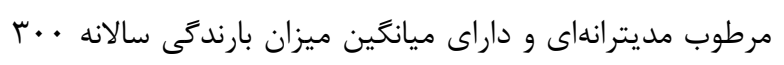

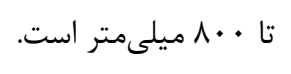

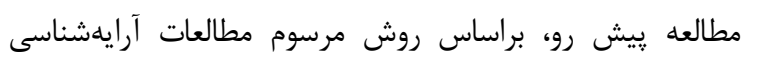

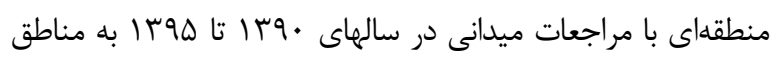

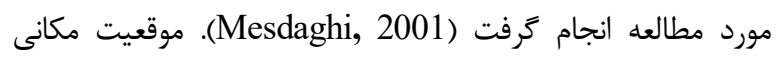

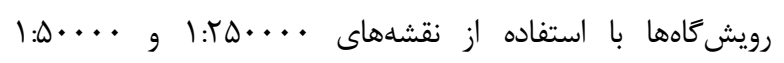

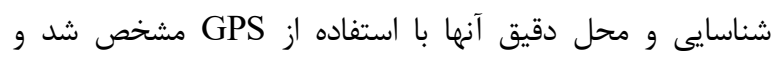

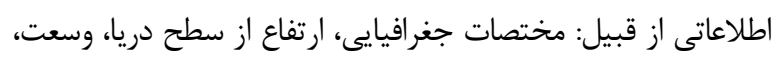

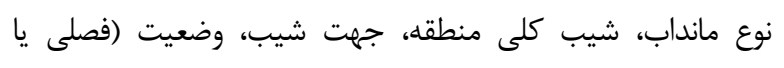

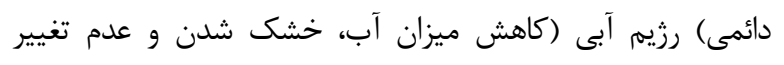

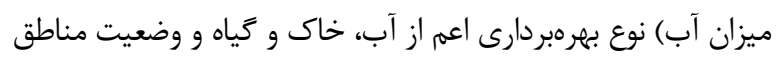

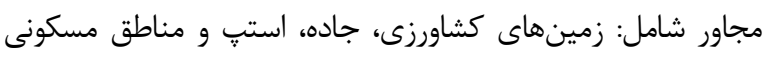



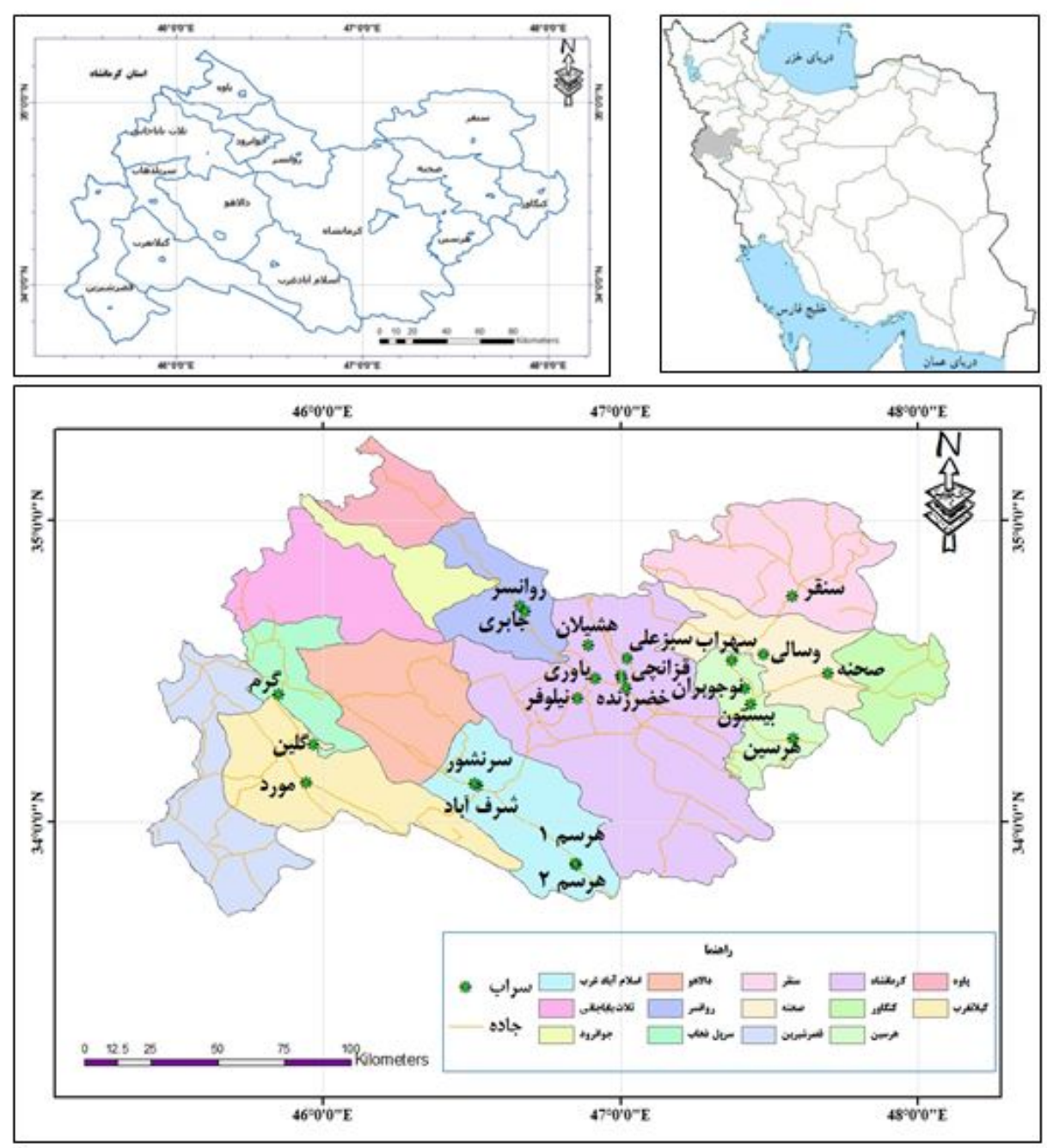

شكل ا- موقعيت جغرافيايى و نقشه منابع آبى استان كرمانشاه.

Figure 1. Geographical location and map of water resources of Kermanshah Province.

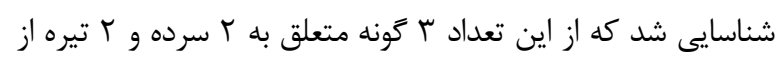

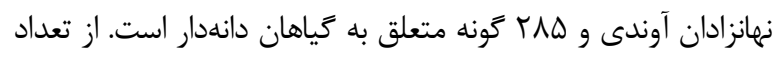

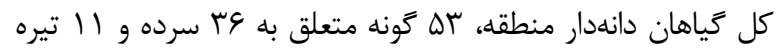

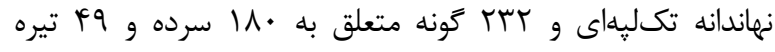

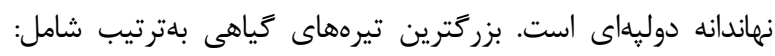

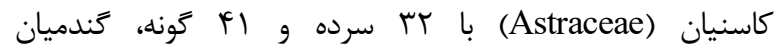

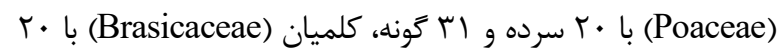

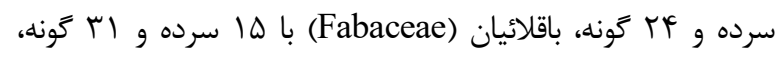

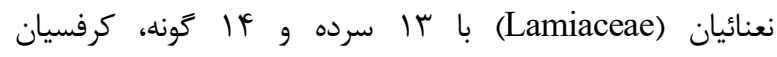
(Apiaceae)

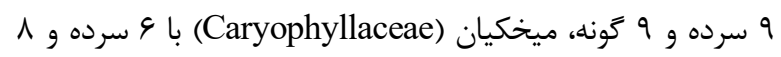

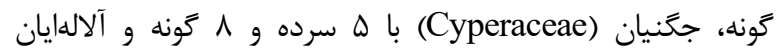
(Ranunculaceae)
استان كرمانشاه داراى تعداد قابل توجهى تالاب، سراب و آبخير و

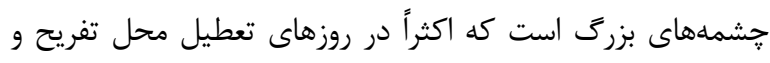

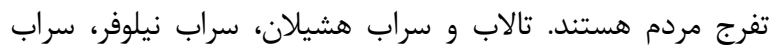

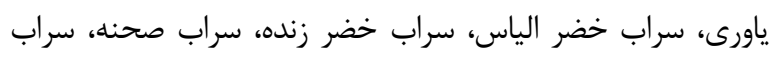

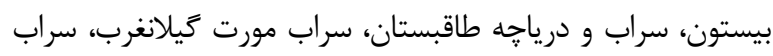

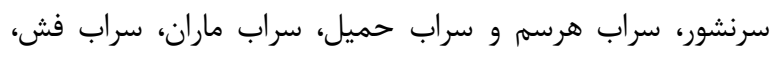

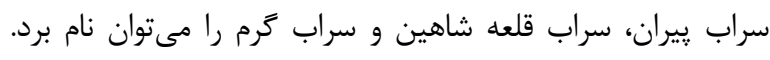

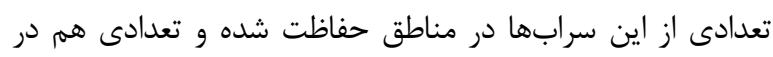

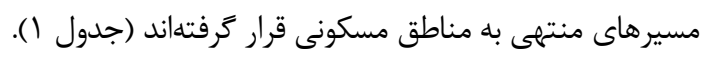
نتايج با بررسى او أمونه جمعآورى شده از اس رويشكاه آبى استان

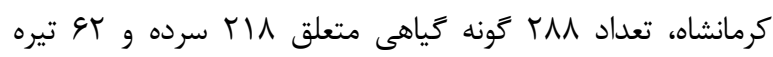


جدول ا - مشخصات مهمترين سرابهاى استان كرمانشاه.

Table 1. Specifications of the most important springs of Kermanshah Province.

\begin{tabular}{|c|c|c|c|c|c|}
\hline دبى متوسط سالانه (ميلىمتر در ثانيه) & طول دورهى آمارى & ار تفاع از سطح دريا (متر) & 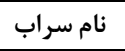 & نام منطقه & 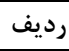 \\
\hline 1490 & 1. & ITIT & طاق بستان & كرمانشاه & 1 \\
\hline 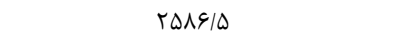 & 19 & $1 \% \Lambda$. & 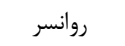 & 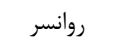 & r \\
\hline $1 \cdots$ & r. & ITrA & 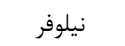 & كرمانشاه & r \\
\hline I IYVA/V & $\wedge$ & GrT & 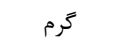 & 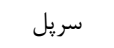 & f \\
\hline $11 \%$. & it & $1 f \ldots$ & 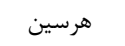 & هرسين & $\Delta$ \\
\hline V৭৭/V & r. & IrAF & 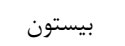 & 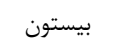 & \& \\
\hline$\Lambda \Delta T / G$ & $\wedge$ & 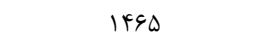 & 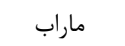 & كنغاور & $\checkmark$ \\
\hline$\notin \notin 1 / \mathrm{V}$ & $\wedge$ & 1940 & 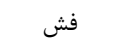 & كنغاور & $\wedge$ \\
\hline $1494 / 9$ & $\checkmark$ & $\wedge \cdots$ & 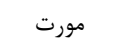 & 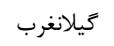 & 9 \\
\hline FAr/A & 4 & 191. & كزنهله & 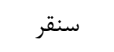 & 1. \\
\hline Frq/D & $r \cdot$ & $|\pi| \cdot$ & خضر الياس & كرمانشاه & 11 \\
\hline
\end{tabular}

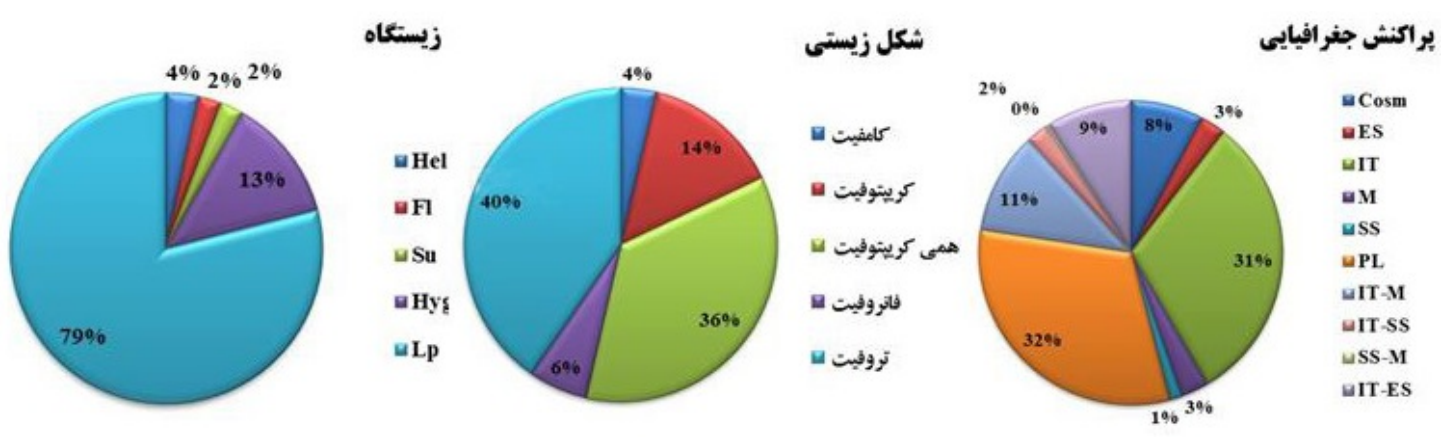

شكل r - نمودارهاى وضعيت رويشى، شكل زيستى و يراكنش جغرافيايى گونههاى گياهى.

Figure 2. Habitat, biological form and corology diagrams of plant species.

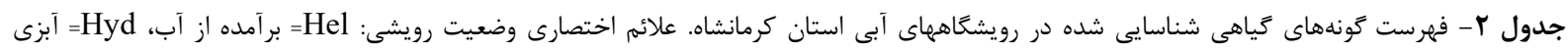

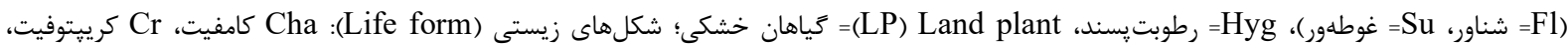

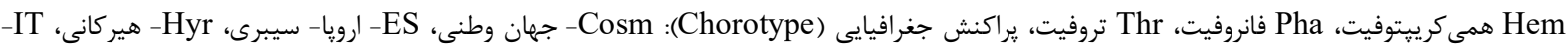

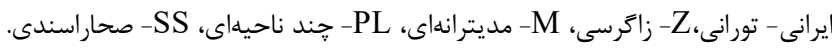

Table 2. List of identified plant species of Kermanshah province wetlands. Abbreviations of vegetation status: Hel= Helophyte, Hyd= Hydrophyte, $\mathrm{Fl}=$ Floating, $\mathrm{Su}=$ Submerged, Hyg= Hygrophyte, LP= Land plant; Life form: $\mathrm{Cha}=\mathrm{Chamaephytes,} \mathrm{Cr}=$ Cryptophytes, Hem= Hemicryptophyts, Pha= Phanerophytes, Thr = Trophytes; Chorotype: Cosm= Cosmopolitan, ES= EuroSiberian, Hyr= Hyrcanian, IT= Irano-Turanian, Z= Zagrosian, $M=$ Mediterranean, $\mathrm{PL}=$ Pluri- regional, $\mathrm{SS}=$ Saharo-Sindian .

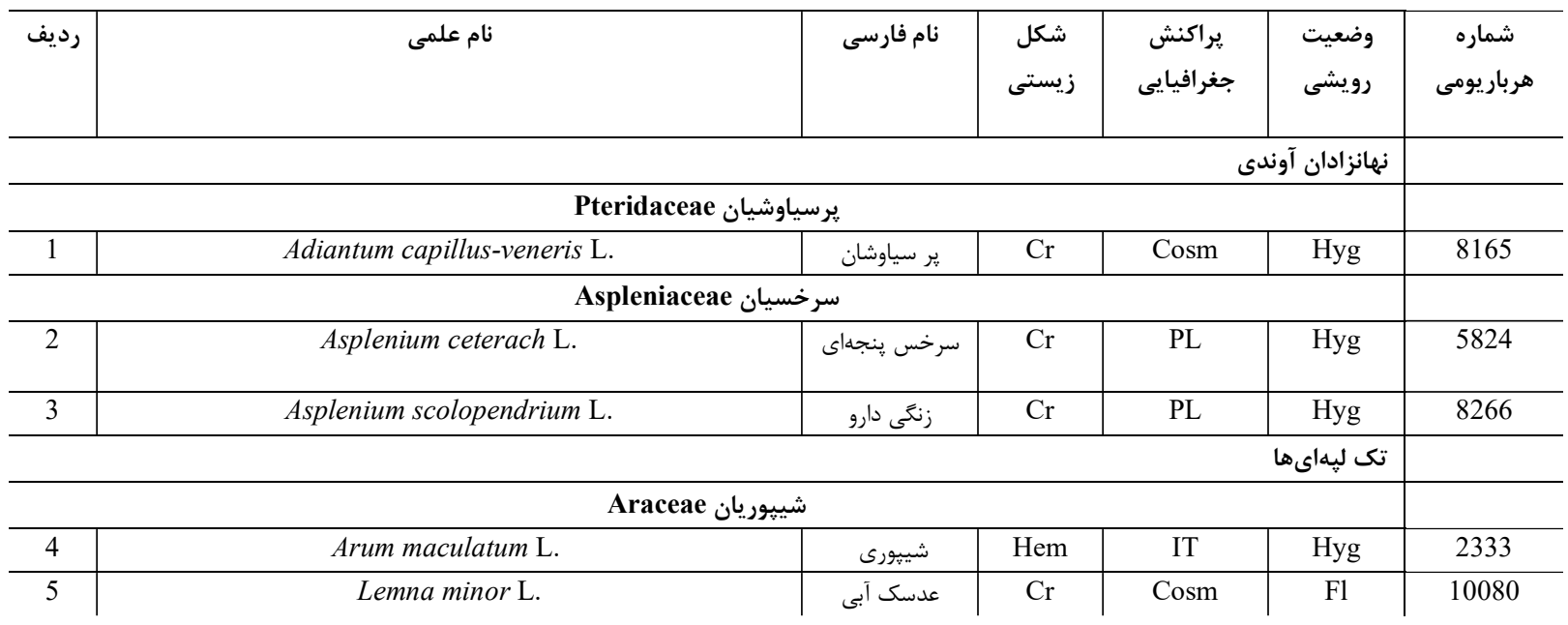


جدول r. ادامه.

Table 2. continued.

\begin{tabular}{|c|c|c|c|c|c|c|}
\hline \multirow{2}{*}{\multicolumn{6}{|c|}{ Asparagaceae مارجوبهايان }} & \multirow[b]{3}{*}{9359} \\
\hline & & & & & & \\
\hline 6 & Bellevalia glauca (Lind1.) Kunth. & تمشكين برك & $\mathrm{Cr}$ & IT & LP & \\
\hline 7 & Leopoldia caucasica (Griseb.) Losinsk. & كلاغك قفقازى & $\mathrm{Cr}$ & IT & LP & 2302 \\
\hline \multicolumn{6}{|c|}{ Butomaceae هزارنىايان } & \\
\hline 8 & Butomus umbellatus L. & 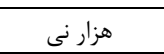 & $\mathrm{Cr}$ & PL & Hyg & 7225 \\
\hline \multicolumn{6}{|c|}{ Colchicaceae } & \\
\hline 9 & Colchicum speciosum Steven & مل حسرت & $\mathrm{Cr}$ & ES & LP & 1790 \\
\hline \multicolumn{6}{|c|}{ Cyperaceae $\quad$ Cَكنيان } & \\
\hline 10 & Bolboschoenus maritimus (L.) Palla & تزك & $\mathrm{Cr}$ & Cosm & Hel & \\
\hline 11 & Carex divisa Huds. & جكَن & Hem & IT - ES & Hyg & 148 \\
\hline 12 & Carex divulsa Stokes & جكن & $\mathrm{Cr}$ & Cosm & Hyg & \\
\hline 13 & Cyperus esculentus $\mathrm{L}$. & اويارسلام & $\mathrm{Cr}$ & $\mathrm{PL}$ & Hyg & 7175 \\
\hline 14 & Cyperus fuscus L. & اويارسلام & Thr & Cosm & Hyg & 8083 \\
\hline 15 & Cyperus laevigatus L. & اويارسلام & $\mathrm{Cr}$ & SS & Hyg & 4031 \\
\hline 16 & Schoenoplectus lacustris (L.) Palla & - & Hem & IT & Hel & 8272 \\
\hline \multicolumn{6}{|c|}{ تخت قورباغهايان Hydrocharitaceae } & \\
\hline 17 & Najas marina All. & تيزك & $\mathrm{Cr}$ & IT & $\mathrm{Su}$ & 8184 \\
\hline \multicolumn{6}{|c|}{ زنبقيان Iridaceae } & \\
\hline 18 & Gladiolus atroviolaceus Boiss. & كَلايول وحشى & $\mathrm{Cr}$ & IT- M & LP & 7339 \\
\hline \multicolumn{6}{|c|}{ سازوئيان Juncaceae } & \\
\hline 19 & Juncus fontanesii subsp. kotschyi (Boiss.) Snoge. & 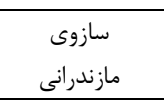 & $\mathrm{Cr}$ & IT & Hyg & 8275 \\
\hline 20 & Juncus inflexus L. & سازوى شلاقى & Hem & IT - ES & Hyg & 8125 \\
\hline 21 & Ornithogalum persicum Hausskn. ex Bornm. & شير مرغ ايرانى & $\mathrm{Cr}$ & IT & LP & 7337 \\
\hline \multicolumn{6}{|c|}{ كندميان Poaceae } & \\
\hline 22 & Aegilops columnaris Zhuk. & كندم نياى & Thr & IT & LP & 1066 \\
\hline 23 & Aegilops umbellulata Zhuk. & كندم نياى & Thr & IT & LP & 6926 \\
\hline 24 & $\begin{array}{l}\text { Alopecurus myosuroides } \\
\text { Huds. }\end{array}$ & 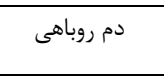 & Thr & PL & LP & 8594 \\
\hline 25 & Avena fatua $\mathrm{L}$. & جو دو سر & Thr & IT & LP & 924 \\
\hline 26 & $\begin{array}{l}\text { Avena sterilis subsp. ludoviciana (Durieu) Gillet \& } \\
\text { Magne }\end{array}$ & 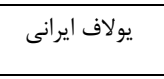 & Thr & IT- M & Hyg & 10080 \\
\hline 27 & Bothriochloa ischaemum (L.) Keng & جارو ينجهاى & Hem & IT- M & Hyg & 3661 \\
\hline 28 & Bromus danthoniae Trin. & جارو علفى هرز & Thr & IT- M & LP & 7074 \\
\hline 29 & Bromus lanceolatus Roth & سرنيزماى & Thr & IT- M & LP & 7078 \\
\hline 30 & Bromus scoparius L. & جارو علفى بى & Thr & IT & LP & 8158 \\
\hline 31 & Bromus sterilis L. & جاروعلفى نازا & Thr & IT- M & LP & 7684 \\
\hline 32 & Bromus tectorum $\mathrm{L}$. & جارو علفى بامى & Thr & Cosm & LP & 8922 \\
\hline 33 & Calamagrostis pseudophragmites (Hall.f.) Koel. & علف نى & Hem & ES & Hyg & 8162 \\
\hline 34 & Catabrosa aquatica (L.) P. Beauv. & علف يیج & $\mathrm{Cr}$ & $\mathrm{PL}$ & Hyg & 9465 \\
\hline 35 & Cynodon dactylon (L.) Pers. & مرغ & $\mathrm{Cr}$ & $\mathrm{PL}$ & LP & 8145 \\
\hline 36 & Festuca myuros L. & دم روباهك & Thr & Cosm & LP & 9412 \\
\hline 37 & Glyceria notata Chevall. & شكرين جيندار & Hem & IT - ES & Hyg & 8100 \\
\hline 38 & Heteranthelium piliferum (Sol.) Hochst. ex Jaub. \& Spach & دكر كل كندمى & Thr & IT & LP & 9597 \\
\hline 39 & Hordeum bulbosum $\mathrm{L}$. & جو & $\mathrm{Cr}$ & IT- M & LP & 8294 \\
\hline
\end{tabular}


جدول r. ادامه.

Table 2. continued.

\begin{tabular}{|c|c|c|c|c|c|c|}
\hline & & & & & & \\
\hline 40 & Hordeum murinum subsp. glaucum (Steud.) Tzvelev & جو هرز & Thr & IT- M & LP & 8154 \\
\hline 41 & Hordeum murinum subsp. leporinum (Link) Arcang. & جو & Thr & Cosm & LP & 8163 \\
\hline 42 & Hordeum murinum $\mathrm{L}$. & جو وحشى & Thr & PL & LP & 7191 \\
\hline 43 & Lolium perenne L. & קمن & Hem & PL & LP & 8193 \\
\hline 44 & Paspalum distichum $\mathrm{L}$. & ارزن باتلاقى & $\mathrm{Cr}$ & PL & Hel & 8292 \\
\hline 45 & Phleum boissieri Bornm. & 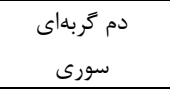 & Thr & IT & LP & 630 \\
\hline 46 & Phragmites australis (Cav.) Trin. ex Steud. & نى - نى قدى قلم & Hem & PL & Hel & 8081 \\
\hline 47 & Poa bulbosa L. & جمن & $\mathrm{Cr}$ & PL & LP & 8299 \\
\hline 48 & Poa persica Trin. & --- & Thr & IT- M & LP & 8152 \\
\hline 49 & Poa pratensis $\mathrm{L}$. & جمن & Thr & IT - ES & LP & 8190 \\
\hline 50 & Polypogon fugax Nees ex Steud. & شال دم ريزان & Thr & $\mathrm{PL}$ & LP & 8192 \\
\hline 51 & Polypogon monspeliensis (L.) Desf. & كندمك & Thr & Cosm & LP & 8155 \\
\hline 52 & Sclerochloa dura (L.) P. Beauv. & جمن زبر & Thr & PL & LP & 8445 \\
\hline \multicolumn{7}{|c|}{ Fotamogetonaceae } \\
\hline 53 & Potamogeton lucens $\mathrm{L}$. & بارهنَ آبى & $\mathrm{Cr}$ & $\mathrm{PL}$ & SU & 8087 \\
\hline 54 & Potamogeton nodosus Poir. & بارهنَ آبى كَره & $\mathrm{Cr}$ & Cosm & SU & 8217 \\
\hline \multicolumn{7}{|c|}{ Typhaceae لوئيان } \\
\hline 55 & Sparganium erectum $\mathrm{L}$. & 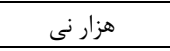 & $\mathrm{Cr}$ & IT & $\mathrm{Fl}$ & 7224 \\
\hline 56 & Typha australis Schum. \& Thonn. & 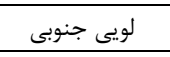 & $\mathrm{Cr}$ & PL & Hel & 7193 \\
\hline \multicolumn{7}{|c|}{ دو ليهاىها } \\
\hline \multicolumn{7}{|c|}{ Amaranthaceae تاج خروسيان } \\
\hline 57 & Amaranthus retroflexus $\mathrm{L}$. & تاج خروس & Thr & IT & LP & 4110 \\
\hline 58 & Caroxylon laricinum (Pall.) Tzvelev. & شور & Hem & PL & Hyg & 10081 \\
\hline 59 & Noaea mucronata (Forssk.) Asch. \& Schweinf & شوخ- خار كو & Cha & IT & LP & 6408 \\
\hline \multicolumn{7}{|c|}{ Sرفسيان Apiaceae $\quad$ S } \\
\hline 60 & Berula erecta (Huds.) Coville & شقاقل آبى & $\mathrm{Cr}$ & $\mathrm{PL}$ & SU & 8115 \\
\hline 61 & Bunium paucifolium DC. & زيره & $\mathrm{Cr}$ & IT & LP & 8783 \\
\hline 62 & Chaerophyllum macropodum Boiss. & جعفرى فرنكى & Hem & IT & LP & 8232 \\
\hline 63 & Chaerophyllum nodosum (L.) Crantz & ساق كراى & Thr & IT - ES & LP & 8220 \\
\hline 64 & Eryngium heldreichii Boiss. & 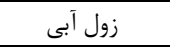 & Hem & PL & LP & 9619 \\
\hline 65 & Lagoecia cuminoides $\mathrm{L}$. & توبى زيره- زيره & Thr & IT- SS & LP & 8157 \\
\hline 66 & $\begin{array}{c}\text { Leiotulus porphyrodiscus (Stapf \& Wettst.) Pimenov \& } \\
\text { Ostr. }\end{array}$ & شقاقل صحرايى & Hem & IT & LP & 10082 \\
\hline 67 & Oliveria decumbens Vent. & لعل كوهستان & Thr & IT- SS & LP & 8241 \\
\hline 68 & $\begin{array}{c}\text { Physospermum cornubiense } \\
\text { (L.) DC. }\end{array}$ & شوكران باغى & Hem & ES & LP & 1417 \\
\hline 69 & Pimpinella affinis Ledeb & ---- & Hem & IT - ES & LP & 1348 \\
\hline 70 & Scandix stellata Banks \& Sol. & شاه ونوس & Thr & IT- M & LP & 8255 \\
\hline 71 & Torilis arvensis (Huds.) Link & ماستونى & Thr & $\mathrm{PL}$ & $\mathrm{LP}$ & 8108 \\
\hline 72 & Torilis leptophylla (L.) Reichenb. & ماستونك نازى & Thr & PL & LP & 8150 \\
\hline
\end{tabular}


جدول r. ادامه.

Table 2. continued.

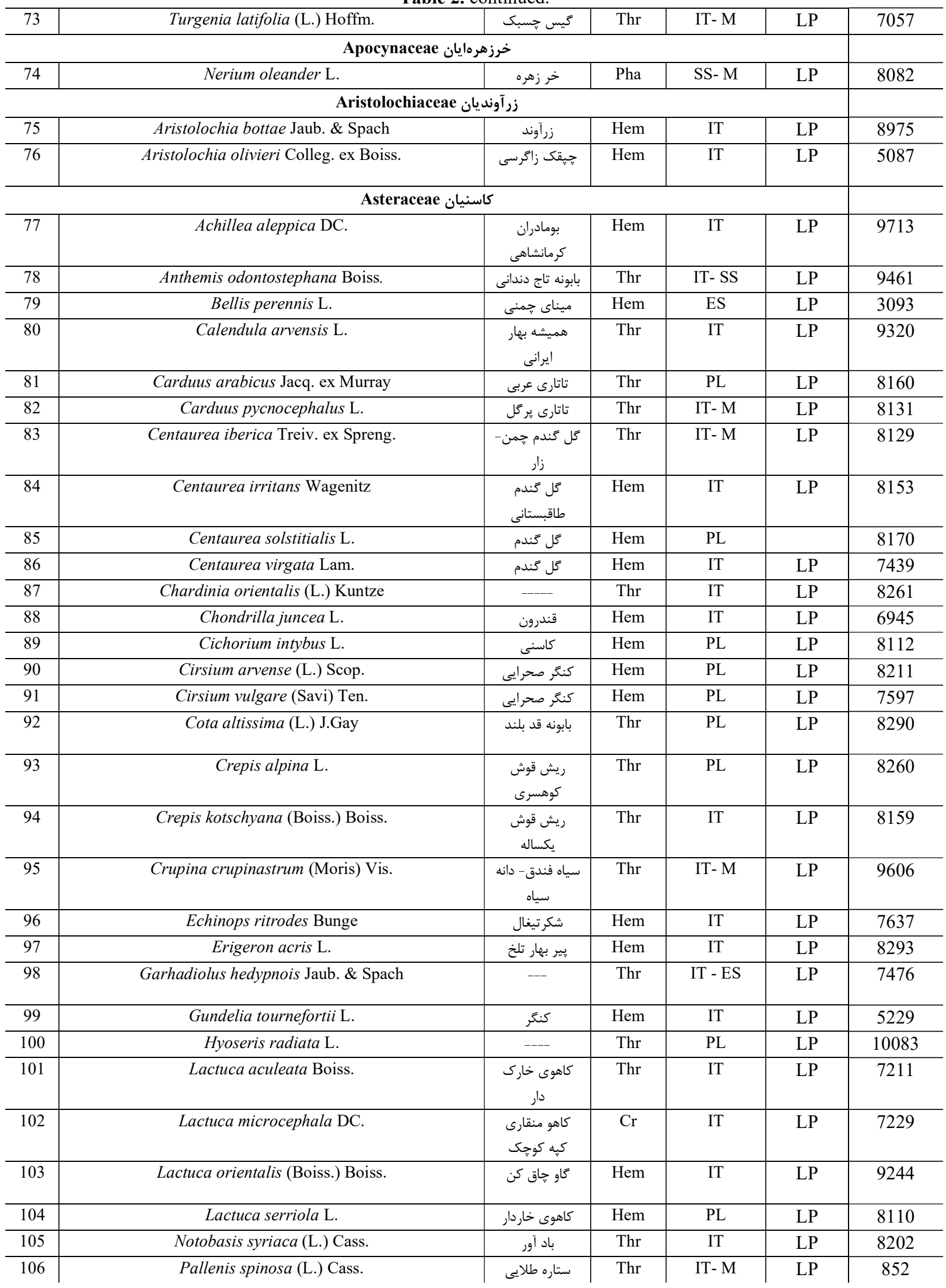


جدول r. ادامه.

Table 2. continued.

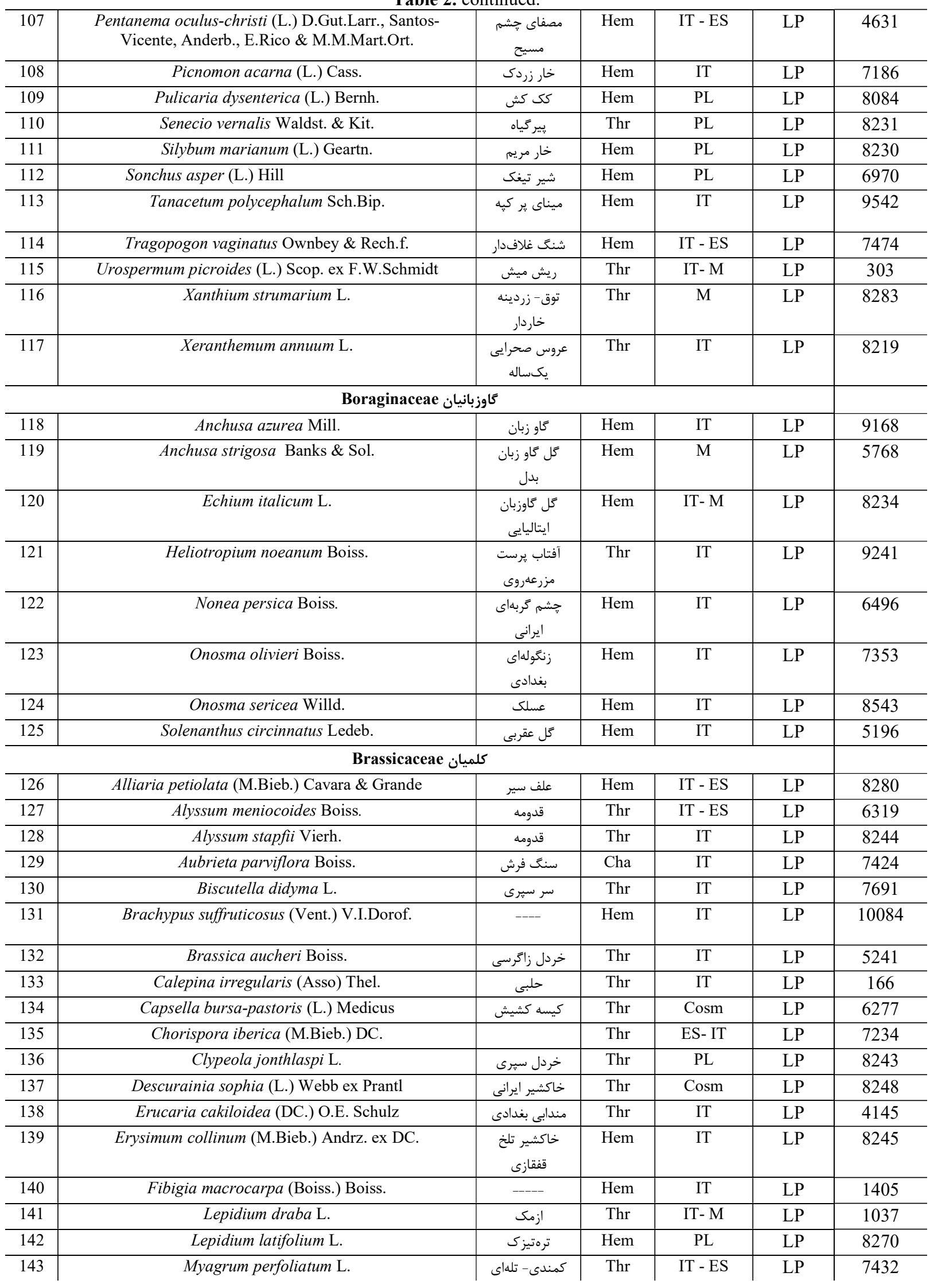


جدول r. ادامه.

Table 2. continued.

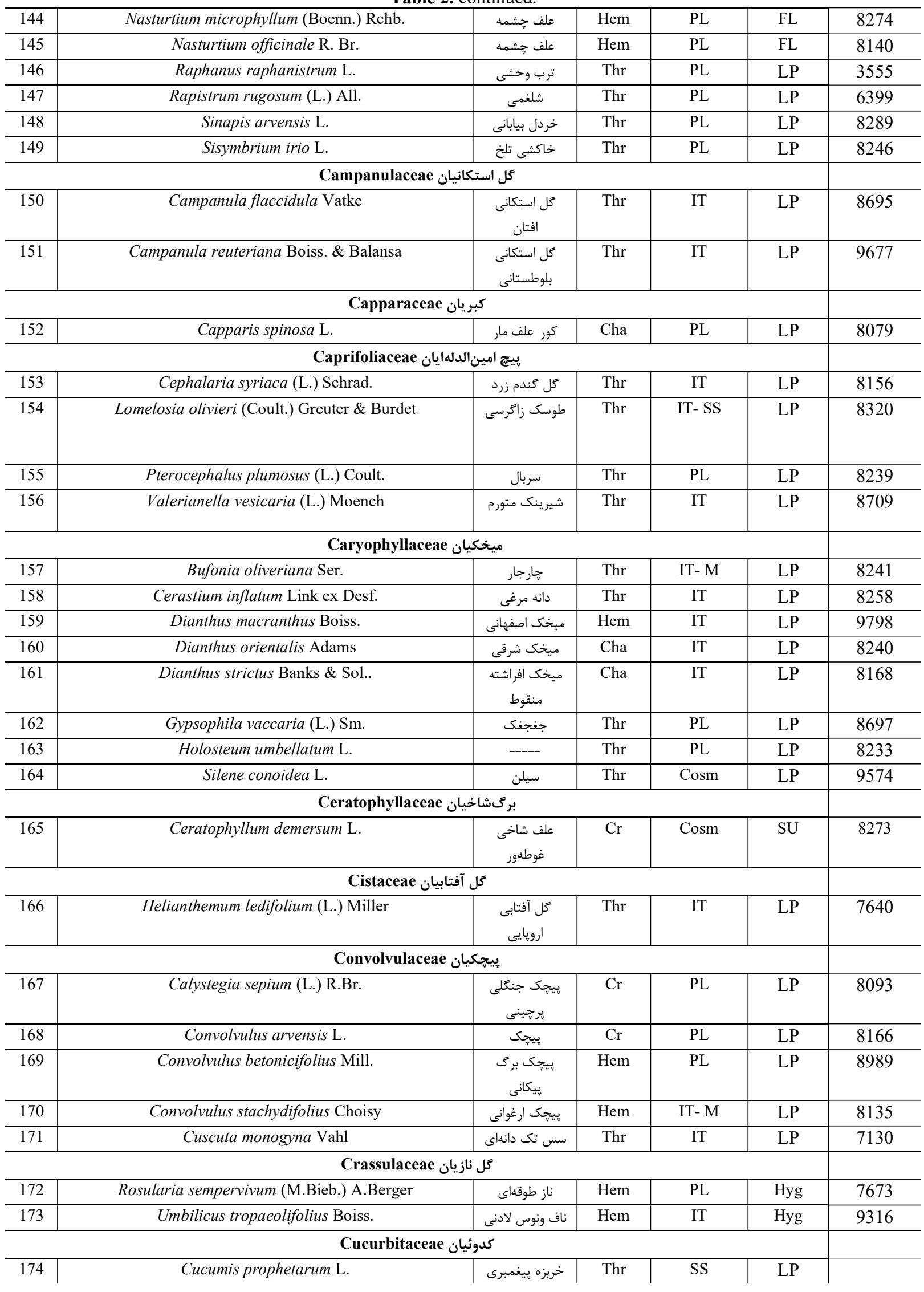


جدول r. ادامه.

Table 2. continued.

\begin{tabular}{|c|c|c|c|c|c|c|}
\hline \\
\hline \multicolumn{7}{|c|}{ Euphorbiaceae فرفيونيان } \\
\hline 175 & Chrozophora tinctoria (L.) A.Juss. & ازرق اورشليمى & Thr & Cosm & LP & 10085 \\
\hline 176 & Euphorbia denticulata Lam. & فرفيون دندانهدار & Hem & IT & LP & 9051 \\
\hline 177 & Euphorbia falcata $\mathrm{L}$. & فرفيون هلالى & Thr & $\mathrm{PL}$ & LP & 1612 \\
\hline 178 & Euphorbia helioscopia L. & فرفيون، شير & Thr & IT & LP & 7463 \\
\hline 179 & Euphorbia peplus L. & فرفيون زكيل دار & Thr & PL & LP & 7720 \\
\hline \multicolumn{7}{|c|}{ Fabaceae باقلائيان } \\
\hline 180 & Anagyris foetida $\mathrm{L}$. & قره تاج & Pha & SS & LP & 3601 \\
\hline 181 & Anthyllis circinnata (L.) D.D.Sokoloff & يونجه اسيانيايى & Thr & $\mathrm{M}$ & LP & 10086 \\
\hline 182 & Astragalus gossypinus Fisch. & كون & Cha & IT & LP & 8298 \\
\hline 183 & Glycyrrhiza glabra L. & شيرين بيان & Hem & IT & LP & 7697 \\
\hline 184 & Lotus corniculatus $\mathrm{L}$. & يونجه پا كلاغى & Hem & PL & LP & 7508 \\
\hline 185 & Medicago minima (L.) Bartal. & يونجه صغير & Thr & $\mathrm{PL}$ & LP & 8223 \\
\hline 186 & Medicago orbicularis (L.) Bartal. & يونجه تكمهاى & Thr & IT- M & LP & 8840 \\
\hline 187 & Medicago sativa $\mathrm{L}$ & يونجه & Hem & IT- SS & LP & 8136 \\
\hline 188 & Melilotus indicus (L.) All. & يونجه زرد يك- & Thr & IT & LP & 6562 \\
\hline 189 & Melilotus officinalis (L.) Lam. & يونجه زرد & Hem & PL & LP & 8139 \\
\hline 190 & Onobrychis altissima Grossh. & اسيرس علوفهاى & Hem & IT - ES & LP & 10087 \\
\hline 191 & Onobrychis crista-galli (L.) Lam. & خروسى تاجى & Thr & IT & LP & 7702 \\
\hline 192 & Ononis spinosa $\mathrm{L}$. & خارخر & Hem & IT & LP & 8119 \\
\hline 193 & Pisum sativum L. & نخودفرنتى - نخودسبز & Thr & IT & LP & 8700 \\
\hline 194 & Prosopis farcta (Banks \& Sol.) J.F.Macbr. & كهورى & Pha & SS & LP & 6799 \\
\hline 195 & Scorpiurus muricatus L. & دم عقبى & Thr & $\mathrm{M}$ & LP & 6652 \\
\hline 196 & Trifolium angustifolium $\mathrm{L}$. & شبدر برى & Thr & $\mathrm{M}$ & LP & 8834 \\
\hline 197 & Trifolium alexandrinum $\mathrm{L}$. & شبدر برسيهم & Thr & $\mathrm{M}$ & LP & 8138 \\
\hline 198 & Trifolium fragiferum $\mathrm{L}$. & 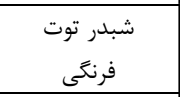 & Hem & IT & LP & 8121 \\
\hline 199 & Trifolium grandiflorum Schreb. & شبدر تماشايى & Thr & $\mathrm{PL}$ & LP & 9527 \\
\hline 200 & Trifolium lappaceum $\mathrm{L}$. & شبدر بابآدمى & Thr & $\mathrm{M}$ & LP & 8137 \\
\hline 201 & Trifolium pilulare Boiss. & شبدر تويى & Thr & IT & LP & 9525 \\
\hline 202 & Trifolium repens $\mathrm{L}$. & شبدر سفيد & Hem & $\mathrm{PL}$ & LP & 6155 \\
\hline 203 & Trifolium resupinatum $\mathrm{L}$. & شبدر ايرانى & Thr & PL & LP & 8195 \\
\hline 204 & Trifolium stellatum $\mathrm{L}$. & شبدر ستارهاى & Thr & IT & LP & 8717 \\
\hline 205 & Trifolium tomentosum $\mathrm{L}$. & شبدر نمدى & Thr & IT & LP & 6249 \\
\hline 206 & Trifolium tumens Stev. ex M.Bieb. & شبدر باد كرده & Hem & ES & LP & 5917 \\
\hline 207 & Trigonella strangulata Boiss. & شنبليله دانه & Thr & IT- M & LP & 10088 \\
\hline 208 & Vicia lens (L.) Coss. \& Germ. & 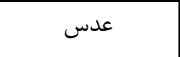 & Thr & IT & LP & 7391 \\
\hline 209 & Vicia narbonensis L. & ماشك برى يهن & Thr & $\mathrm{M}$ & LP & 7268 \\
\hline 210 & Vicia sativa $\mathrm{L}$. & ماشك-كاودانه & Thr & PL & LP & 8961 \\
\hline \multicolumn{7}{|c|}{ Geraniaceae شمعدانيان } \\
\hline 211 & Erodium malacoides (L.) L'Hér. & نوك لِّ لكى & Thr & $\mathrm{M}$ & LP & 8225 \\
\hline
\end{tabular}


جدول r. (ادامه.

Table 2. continued.

\begin{tabular}{|c|c|c|c|c|c|c|}
\hline \\
\hline 212 & Geranium lucidum L. & سوزن تويان & Thr & PL & LP & 8236 \\
\hline 213 & Geranium tuberosum L. & 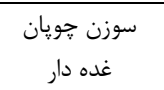 & $\mathrm{Cr}$ & IT- M & LP & 5191 \\
\hline \multicolumn{7}{|c|}{ Haloragaceae هزار بركَيان } \\
\hline 214 & Myriophyllum spicatum $\mathrm{L}$. & سنبلهاى سوسى & $\mathrm{Cr}$ & Cosm & SU & 8101 \\
\hline \multicolumn{7}{|c|}{ Fypericaceae كل راعيان } \\
\hline 215 & Hypericum scabrum L. & دل ديهى راعى & Hem & IT & LP & 5916 \\
\hline \multicolumn{7}{|c|}{ Juglandaceae كردوئيان } \\
\hline 216 & Juglans regia $\mathrm{L}$. & 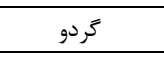 & Pha & IT - ES & LP & 203 \\
\hline \multicolumn{7}{|c|}{ نعنائيان Lamiaceae } \\
\hline 217 & Ajuga chamaecistus Ging. ex Benth. & 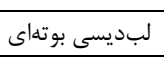 & Cha & IT & LP & 7334 \\
\hline 218 & Lamium amplexicaule $\mathrm{L}$. & غربيلك & Thr & IT - ES & LP & 8249 \\
\hline 219 & Lycopus europaeus $\mathrm{L}$. & كاو زبان ارويايى & Hem & PL & LP & 8284 \\
\hline 220 & Mentha longifolia $(\mathrm{L}$.$) Hudson$ & نعنا وحشى-يونه & Hem & $\mathrm{PL}$ & Hyg & 8106 \\
\hline 221 & Mentha pulegium $\mathrm{L}$. & يونه & Hem & PL & Hyg & 8095 \\
\hline 222 & Nepeta cataria L. & يونه ساى & Hem & PL & LP & 4091 \\
\hline 223 & Origanum vulgare $\mathrm{L}$. & مرزنجوش & Cha & IT - ES & LP & 8279 \\
\hline 224 & Phlomis lanceolata Boiss. \& Hohen. & سرنيز بره & Hem & IT & LP & 7799 \\
\hline 225 & Salvia palaestina Benth. & مريم كلى & Hem & PL & LP & 5538 \\
\hline 226 & Scutellaria pinnatifida A.Ham. & بشقابى سنبلهاى & Hem & IT & LP & 3505 \\
\hline 227 & Stachys inflata Benth. & سنبلهاى ارغوانى & Hem & IT & LP & 9399 \\
\hline 228 & Teucrium polium $\mathrm{L}$. & مريم نخودى اسيانيى & Hem & IT- M & LP & 8758 \\
\hline 229 & Vitex agnus-castus $\mathrm{L}$. & وناكروامنى درخت & Pha & IT & Hyg & 6189 \\
\hline 230 & Ziziphora capitata $\mathrm{L}$. & كاكوتى سرسان & Thr & IT & LP & 9684 \\
\hline \multicolumn{7}{|c|}{ حنائيان Lythraceae } \\
\hline 231 & Lythrum salicaria L. & 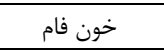 & Hem & IT - ES & Hyg & 8116 \\
\hline \multicolumn{7}{|c|}{ ينيركيان Malvaceae } \\
\hline 232 & Alcea kurdica (Schltdl.) Alef. & ختمى كردى & Hem & PL & LP & 8767 \\
\hline 233 & Althaea officinalis $\mathrm{L}$. & ختمى & Hem & PL & LP & 8213 \\
\hline 234 & Hibiscus trionum L. & ختمى سه رنغ & Thr & PL & LP & 6174 \\
\hline 235 & Malva neglecta Wallr. & 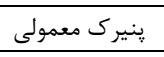 & Hem & PL & LP & 7796 \\
\hline 236 & Malva nicaeensis All. & 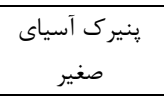 & Hem & PL & LP & 8149 \\
\hline \multicolumn{7}{|c|}{ توتيان Moraceae } \\
\hline 237 & Ficus carica $\mathrm{L}$. & 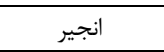 & Pha & IT- M & LP & 8185 \\
\hline 238 & Morus alba $\mathrm{L}$. & توت سفيد & Pha & IT & LP & 10089 \\
\hline \multicolumn{7}{|c|}{ Nitrariaceae قره داغيان } \\
\hline 239 & Peganum harmala $\mathrm{L}$. & اسيند & Hem & PL & LP & 8134 \\
\hline \multicolumn{7}{|c|}{ Nymphaeaceae نيلوفر آبيان } \\
\hline 240 & Nuphar lutea (L.) Sm. & نيلوفر آبى & $\mathrm{Cr}$ & PL & FL & 8178 \\
\hline \multicolumn{7}{|c|}{ زيتونيان Oleaeceae } \\
\hline 241 & Olea europaea L. & زيتون خوراكى & Pha & IT- M & LP & 6960 \\
\hline
\end{tabular}


جدول r. ادامه.

Table 2. continued.

\begin{tabular}{|c|c|c|c|c|c|c|}
\hline \\
\hline \multicolumn{6}{|c|}{ كل مغربيان Onagraceae } & \multirow[b]{2}{*}{8206} \\
\hline 242 & Epilobium hirsutum $\mathrm{L}$. & بيد علفى كركى & $\mathrm{Cr}$ & PL & Hyg & \\
\hline 243 & Epilobium minutiflorum Hausskn. & بيد علفى فروتن & Hem & IT & Hyg & 8267 \\
\hline \multicolumn{7}{|c|}{ Orobanchaceae } \\
\hline 244 & Orobanche aegyptiaca Pers. & كل جاليز مصرى & Thr & ES & LP & 8714 \\
\hline \multicolumn{7}{|c|}{ Aقايقيان Papaveraceae } \\
\hline 245 & Fumaria parviflora Lam. & شاه تره & Thr & Cosm & LP & 7420 \\
\hline 246 & Papaver macrostomum Boiss. \& A.Huet & 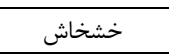 & Thr & PL & LP & 8237 \\
\hline 247 & Papaver refractum (DC.) K.-F.Günther & كل عروسك & Thr & IT & LP & 7046 \\
\hline \multicolumn{7}{|c|}{ Plantaginaceae بارهنَيان } \\
\hline 248 & Plantago lanceolata $\mathrm{L}$. & بارهنَ نيزه اى & Hem & PL & Hyg & 8172 \\
\hline 249 & Plantago major $\mathrm{L}$. & بارهنگ & Hem & PL & Hyg & 8228 \\
\hline 250 & Veronica anagallis-aquatica $\mathrm{L}$. & سيزاب آبى & Hem & Cosm & Hel & 8199 \\
\hline \multicolumn{7}{|c|}{ Slumbaginaceae كلاه ميرحسنيان } \\
\hline 251 & Plumbago europaea $\mathrm{L}$. & علف سربى & Hem & PL & Hyg & 6188 \\
\hline \multicolumn{7}{|c|}{ علف هفت بنديان Polygonaceae } \\
\hline 252 & Persicaria amphibia (L.) Delarbre & علف هفت بند & Thr & Cosm & Hel & 8680 \\
\hline 253 & Persicaria lapathifolia (L.) Delarbre & علف هفت بند & Thr & $\mathrm{PL}$ & LP & 8180 \\
\hline 254 & Polygonum hyrcanicum Rech.f. & هفت بند خزرى & Hem & PL & LP & 8227 \\
\hline 255 & Rumex crispus L. & ترشك & Hem & PL & LP & 8254 \\
\hline 256 & Rumex tuberosus L. & ترشك & $\mathrm{Cr}$ & IT - ES & LP & 836 \\
\hline \multicolumn{7}{|c|}{ بامجاليان Primulaceae } \\
\hline 257 & Lysimachia arvensis (L.) U.Manns \& Anderb. & 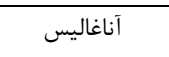 & Thr & PL & LP & 6937 \\
\hline \multicolumn{7}{|c|}{ Ranunculaceae آلالدايان } \\
\hline 258 & Adonis dentata Delile & "جشم خروس ايرانى & Thr & $\mathrm{PL}$ & LP & 7483 \\
\hline 259 & Anemone biflora DC. & شقايق نعمانى & $\mathrm{Cr}$ & PL & LP & 4956 \\
\hline 260 & Ranunculus arvensis $\mathrm{L}$. & آلاله وحشى & Thr & IT & $\mathrm{Hel}$ & 7367 \\
\hline 261 & Ranunculus asiaticus $\mathrm{L}$. & آلاله ايرانى & $\mathrm{Cr}$ & IT-SS & Hyg & 8041 \\
\hline 262 & Ranunculus constantinopolitanus (DC.) d'Urv. & آلاله & Hem & IT- M & Hyg & 10090 \\
\hline 263 & Ranunculus isthmicus Boiss. & آلاله & Hem & IT- M & Hyg & 10091 \\
\hline 264 & Ranunculus kochii Ledeb. & --- & $\mathrm{Cr}$ & IT & Hyg & 2942 \\
\hline 265 & Ranunculus rionii Lagger & 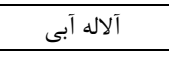 & Thr & IT- M & FL & 9467 \\
\hline \multicolumn{7}{|c|}{ عنابيان Rhamnaceae } \\
\hline 266 & Rhamnus kurdica Boiss. \& Hohen. & سياه تنكرس & Pha & IT - ES & LP & 9806 \\
\hline \multicolumn{7}{|c|}{ Rosaceae } \\
\hline 267 & Agrimonia eupatoria $\mathrm{L}$ & 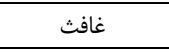 & Hem & IT - ES & LP & 8126 \\
\hline 268 & Aria graeca (Lodd. ex Spach) M.Roem. & بارانك & Pha & PL & LP & 7171 \\
\hline 269 & Fragaria vesca $\mathrm{L}$. & توت فرنغى & Hem & ES & LP & 10092 \\
\hline 270 & Geum urbanum $\mathrm{L}$. & علف ميارك & $\mathrm{Cr}$ & ES & LP & 10093 \\
\hline 271 & Potentilla reptans $\mathrm{L}$. & ينجاه برك رونده & Hem & IT - ES & LP & 8142 \\
\hline 272 & Prunus microcarpa C.A.Mey. & آلبالو وحشى & Pha & IT - ES & LP & 10094 \\
\hline 273 & Rosa canina $\mathrm{L}$ & نسترن وحشى & Pha & $\mathrm{PL}$ & LP & 8341 \\
\hline 274 & Rubus creticus Tourn. ex L. & تمشك & Pha & IT - ES & Hyg & 10095 \\
\hline
\end{tabular}


جدول r. ادامه.

Table 2. continued.

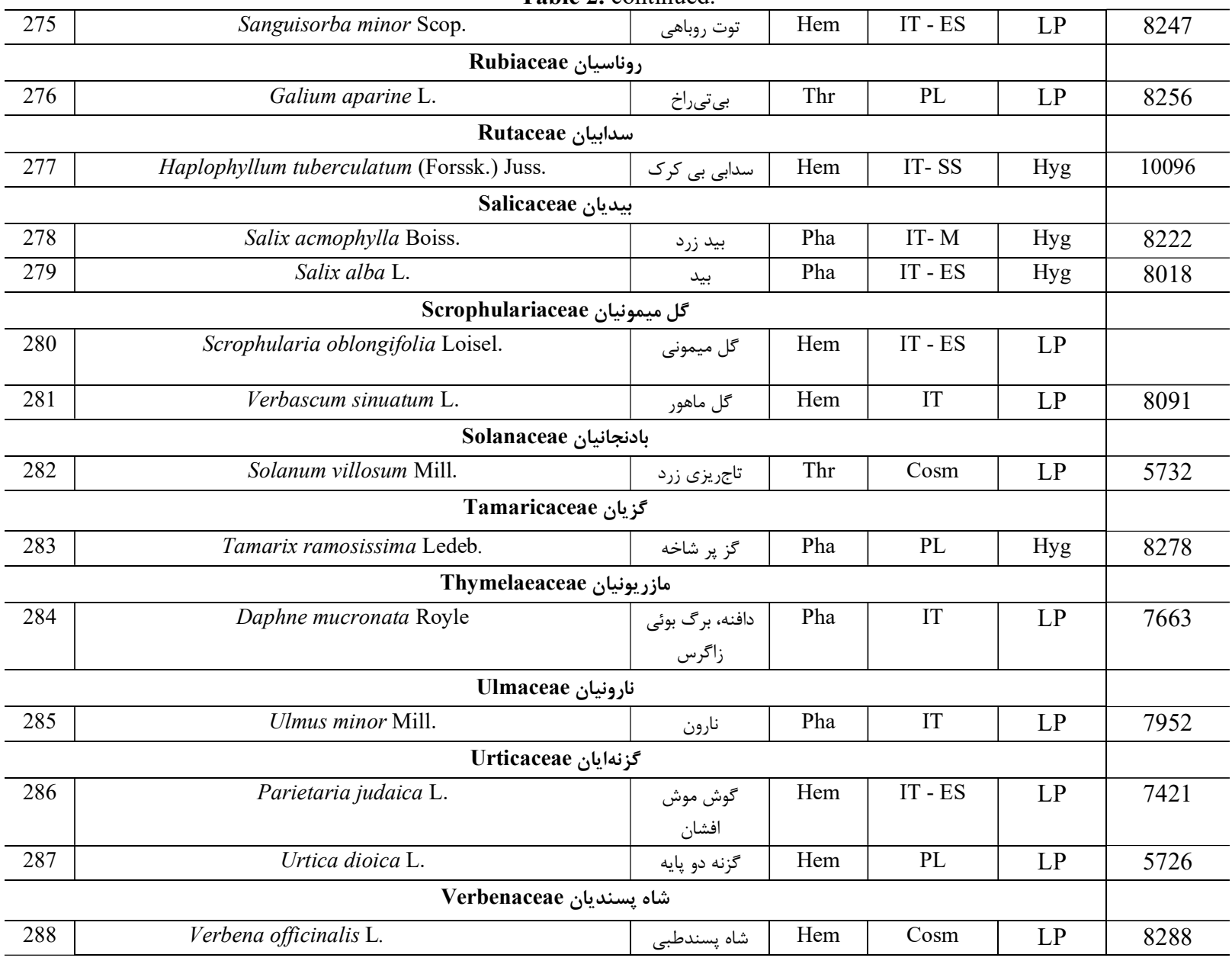

(Plantaginaceae)، (Onagraceae)، كل مغربيان (Crassuaceae)

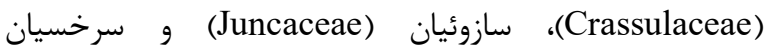
(هر يك با ץ كونه) و تيرههاى يرسياوشيان (Aspleniaceae)

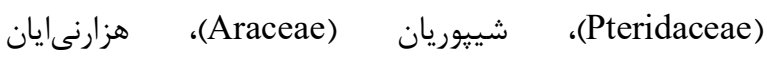

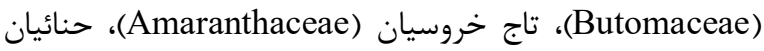
(Blhraceae)

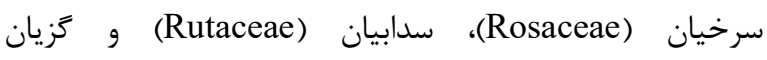

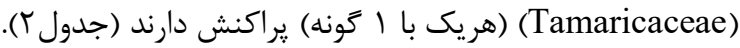

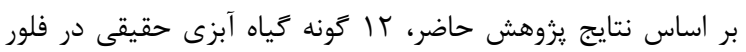

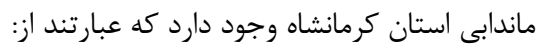
Lemna minor L. (Lemnaceae), Potamogeton lucens L., Potamogeton nodosus Poir. (Potamogetonaceae), Sparganium erectum L. (Typhaceae), Berula erecta Huds.Coville (Apiaceae), Nasturtium microphyllum (Boenn.) Rchb., Nasturtium officinale R.Br. (Brassicaceae), Ceratophyllum demersum L. (Ceratophyllaceae), Myriophyllum spicatum L. (Halograceae), Nuphar lutea (L.) Sm.

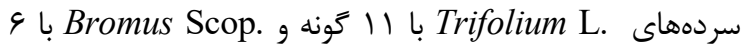

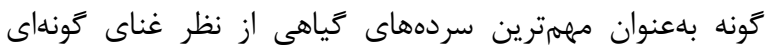

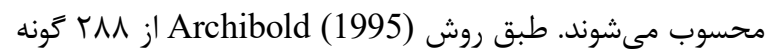

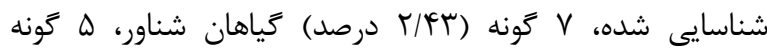

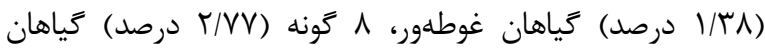

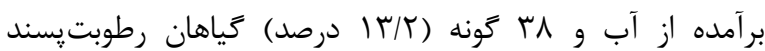

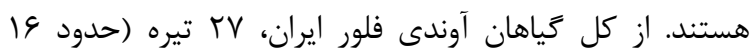
درصد) هيدروفيتهاى واقعى هستند (Safikhani et al., 2018).

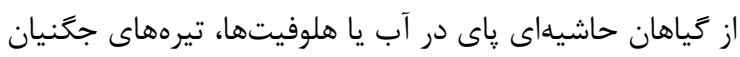
(Cyperaceae)

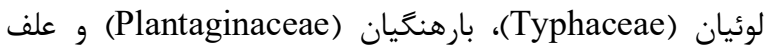

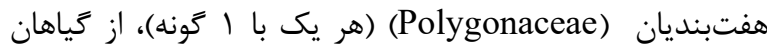

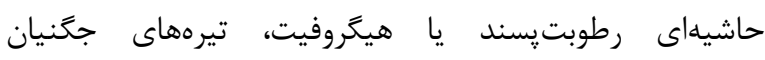
(Cyperaceae)

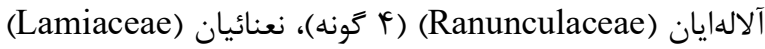

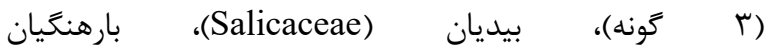


آب، گياهان، جانوران، عناصر غذايى و روابط متقابل بين آنها براى هميشه حفظ و تضمين كردد.

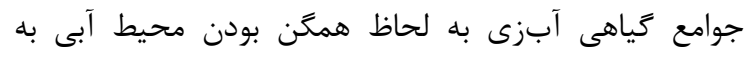

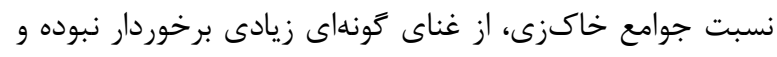

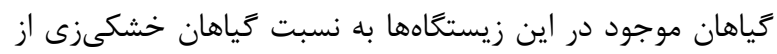
تخصص ساختارى كمترى برخوردارند. شكل زيستى كياهنان

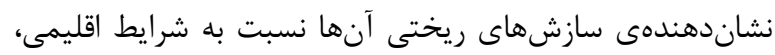

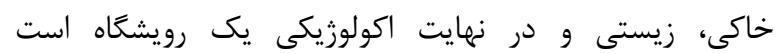
.(Archibold, 1995)

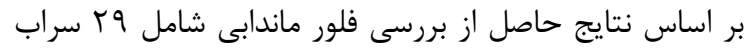

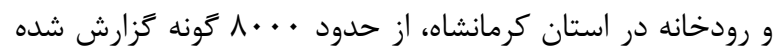
(Assadi, 2019)

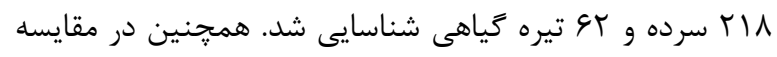
با هال المونه فلور استان كرمانشاه (Jalilian et al., 2017)،

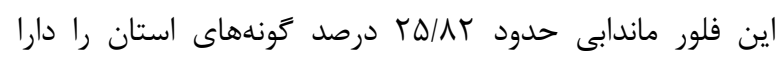

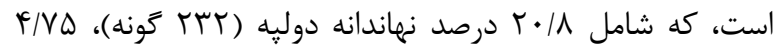

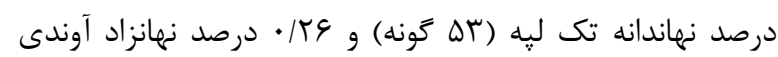

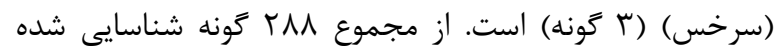

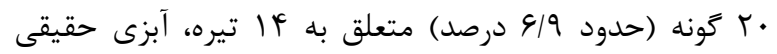

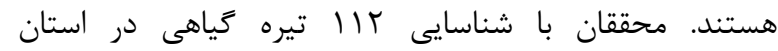

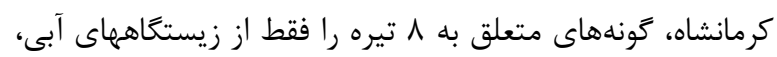
TI

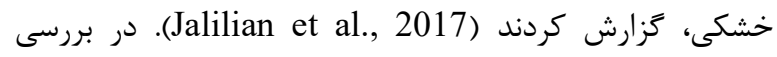

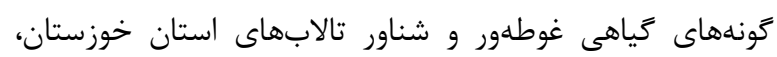

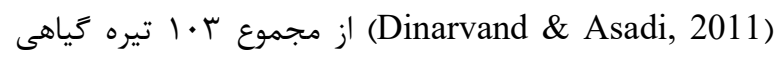

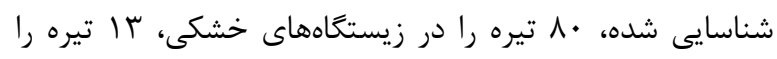

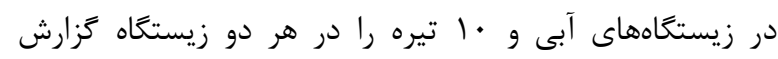

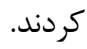

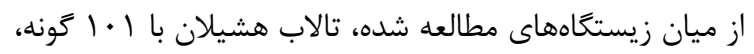

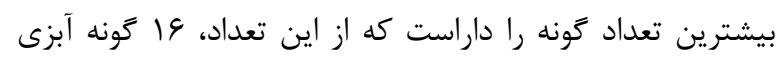

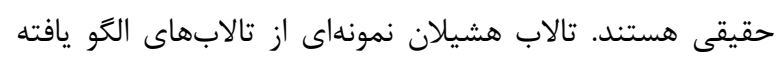

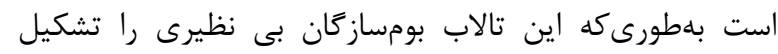
مى دهد كه به صورت تركيبى از جزيرك بهاى خشك آنس (هاموكها)

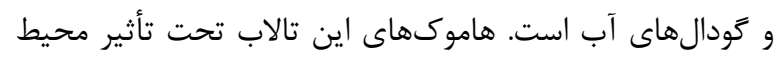

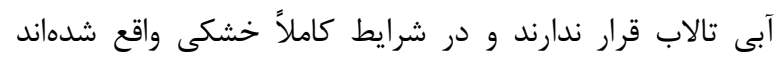

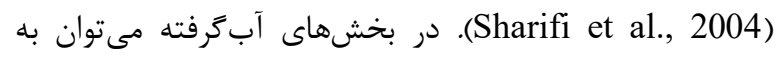
كونههاى: بارهنَ آبى Potamogeton lucens، كَنهایى علف

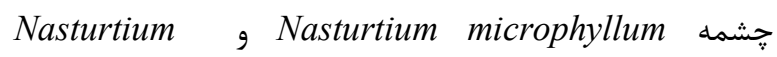
Lemna minor آبى، علف شاخى غوطه ور ، Phragmites australis نeratophyllum demersum
(Nymphaeaceae), Ranunculus rionii Lagger (Ranunculaceae), Najas marina All. (Hydrocharitaceae).

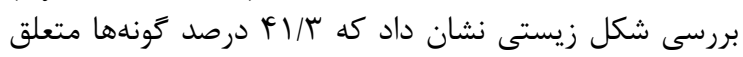

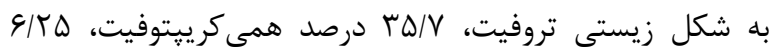

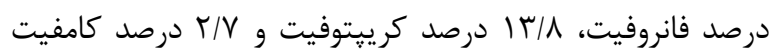

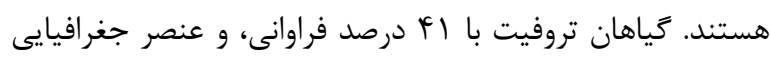

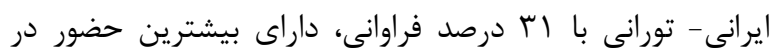

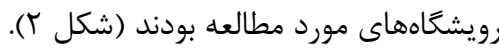

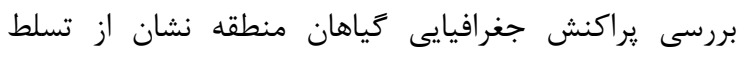

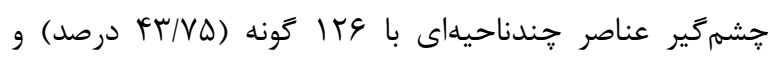

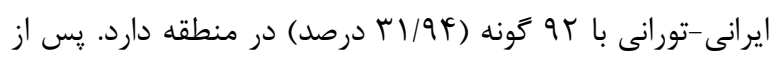

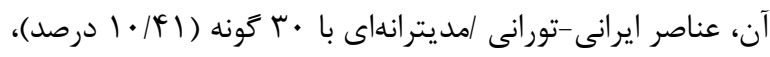

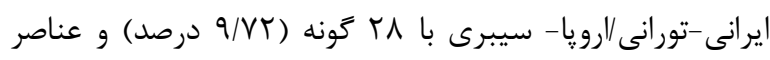

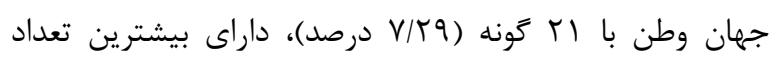

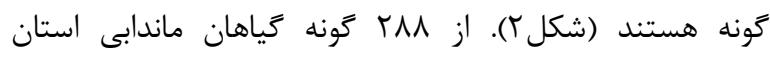

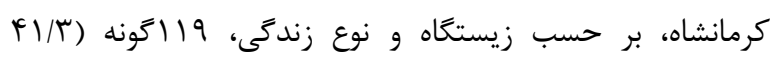

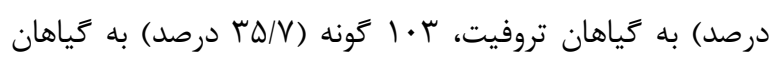

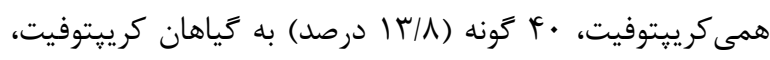

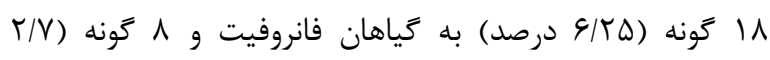
درصد) به كياهان كامفيت تعلق دارند. در شكل ب انمودار دايرهاي

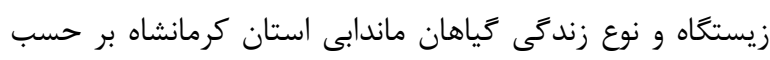
درصد نشان داده شده است.

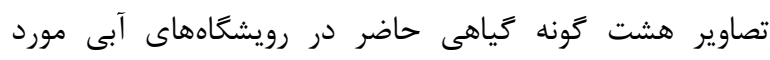
بررسى در شكل ب ارائه شده است.

\section{بحث و نتيجه كيرى}

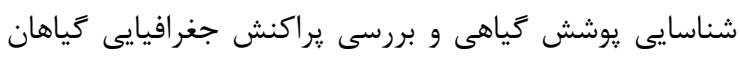

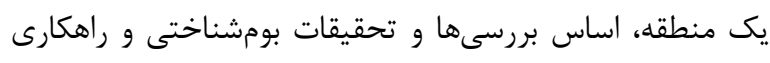

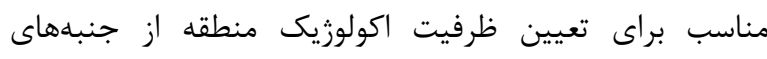

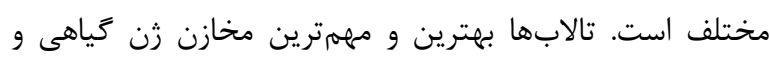

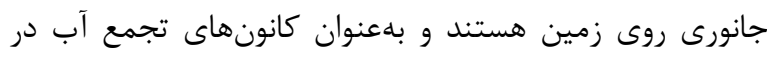

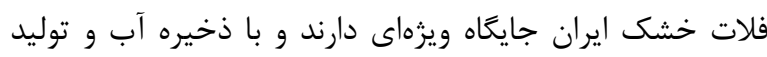

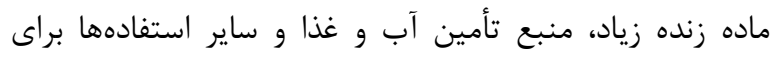

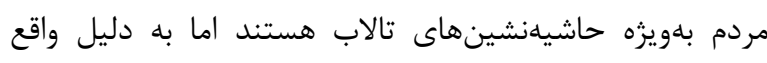

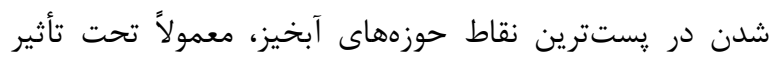

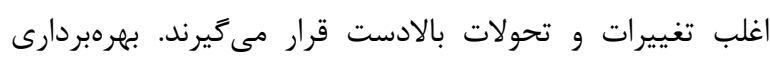

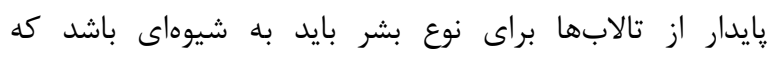

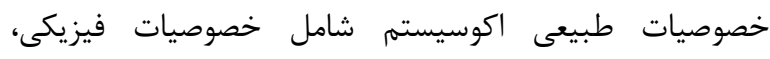
شيميايى و بيولوزيكى اجزاء تشكيل دهنده اكوسيستم نظير خاك، 

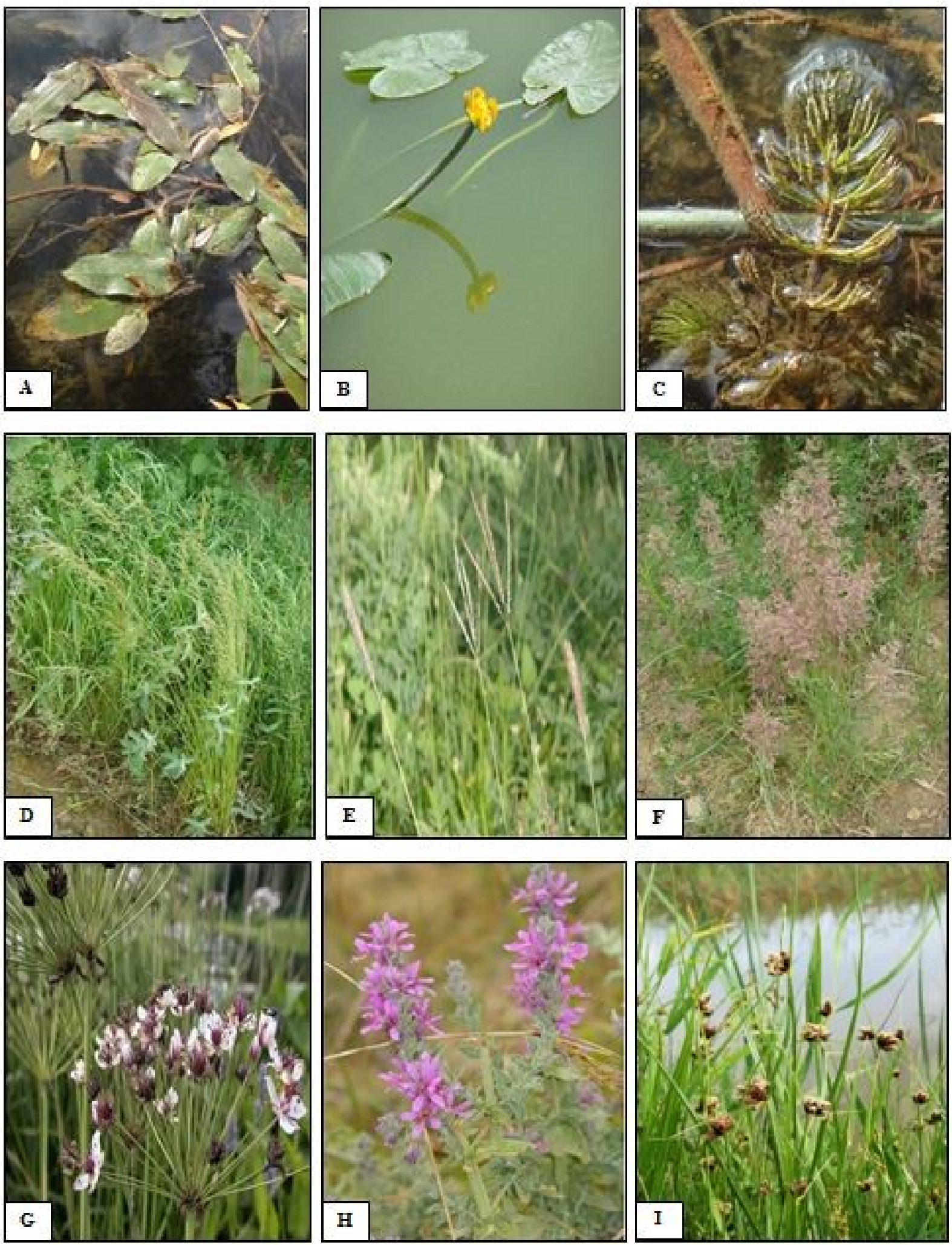

شكل r- تصاوير 9 گونه گياهى حاضر در رويشًاههاى مورد بررسى.

Figure 3. Photographs of nine plant species in the studied habitats, A. Potamogeton nodusus. B. Nuphar lutea. C. Ceratophyllum demersum. D. Catabrosa aquatic. E. Bothriochloa ischaemum. F. Calamogeristis pseudo. G. Butomus umbellatus. H. Lythrum salicaria. I. Bolboschoenus maritimus. 
et al., 2018; Ghahremaninejad \& Agheli, 2009; .(Mansouri et al., 2013; Ravanbakhsh et al., 2007 Fونهاي Ranunculus arvensis و مانهای كياهان تروفيت آبزى در ماندابهاى استان كرمانشاه هستند

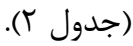

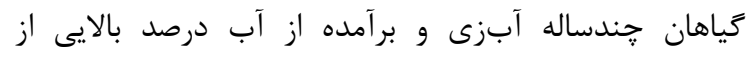

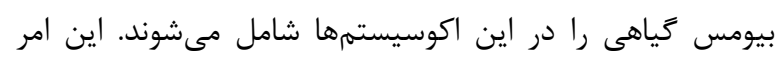

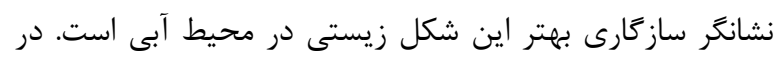

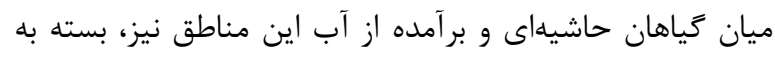

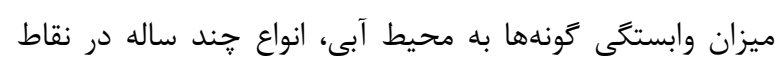

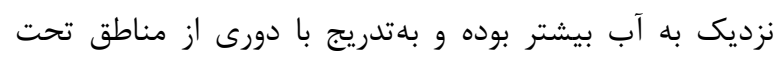

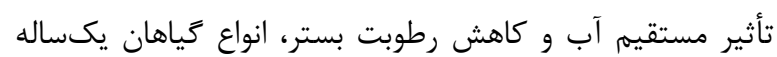
افزايش مى تابند.

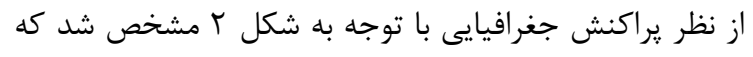

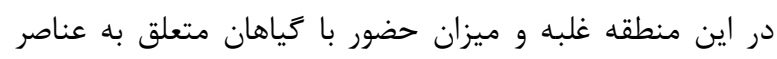

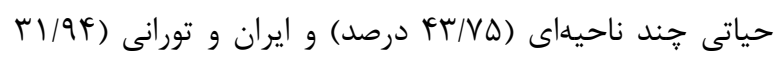

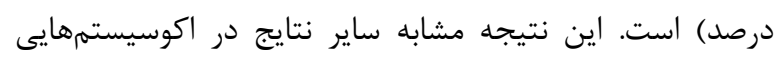

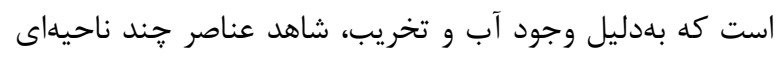

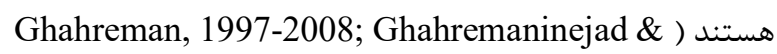
(Agheli, 2009 ). در مطالعه فلور ماندابى استان همدان نيز

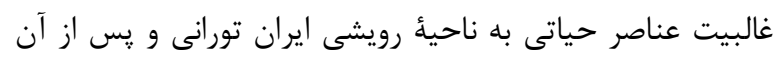

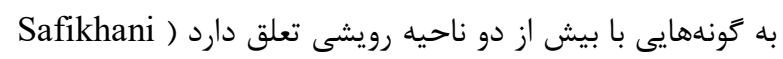

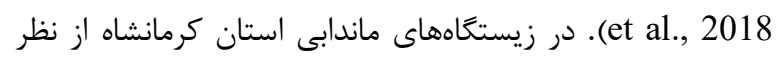

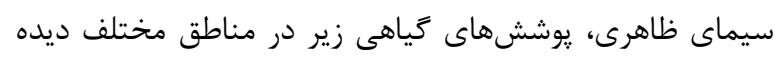

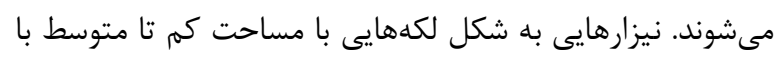

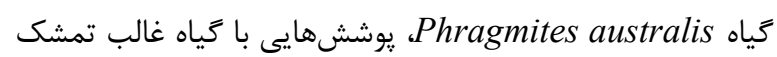
Rubus creticus كونه غالب بيد علفى كركى Epilobium hirsutum

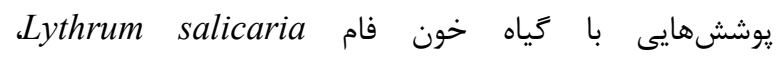

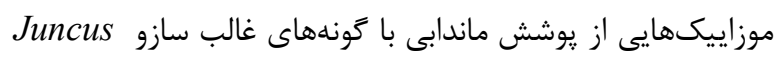
Cyperus fuscus inflexus Mentha Cyperus divulsa, Cyperus esculentus كه يونهزارها را تشكيل مى إهند و د در حاشيه

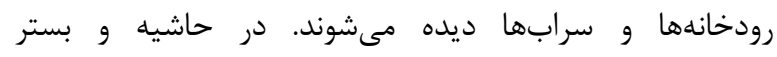
رودخانهاى فصلى و دائمى مناطق كرمسيرى استان كيان

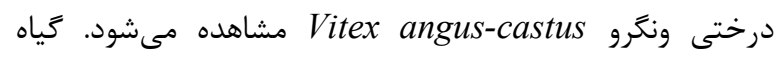

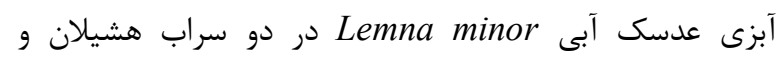

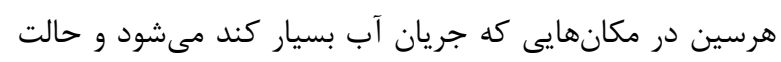

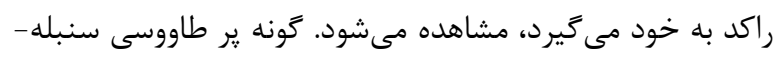

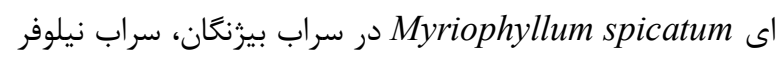

لويى Typha australis، جكن Carex divulsa و در جزاير خشكىزى به كونهایى: تمشك Rubus creticus، بيد Talix alba،

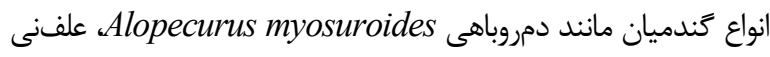
Polypogon Calamagrostis pseudophragmites Tatabrosa aquatic monspeliensis آنجايى كه تالاب هشيلان در زمينهاى كشاورزى اطراف آن محصور

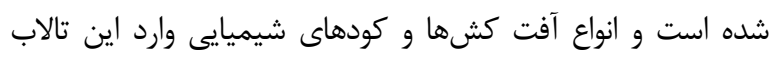

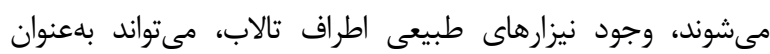
سيستم طبيعى بايش آبهاى آلوده عمل نمايد.

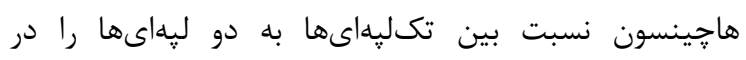

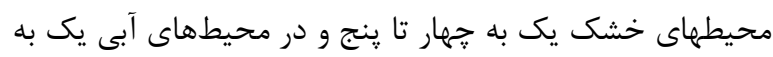

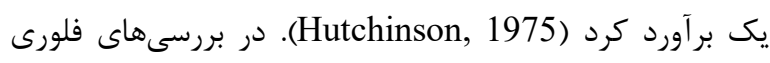

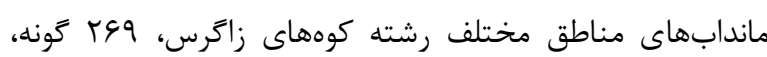

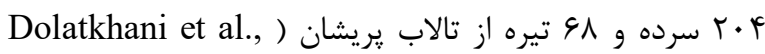

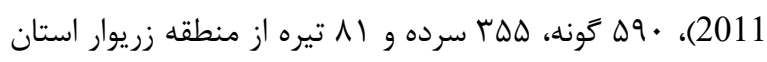

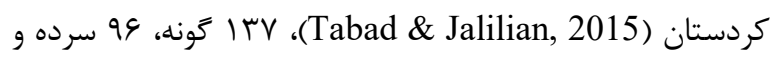

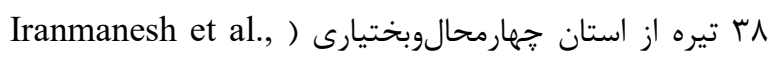

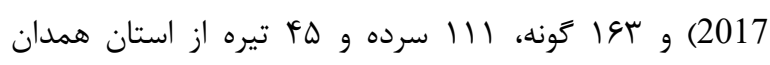
شناسايى شد (Safikhani et al., 2018). بررسى حاضر نشان داد فلور ماندابى استان كرمانشاه، تيرههاى (Sas تAsteraceae تنوع از نظر تعداد گونه را دارند. تيرههاى Asteraceae و Poaceae

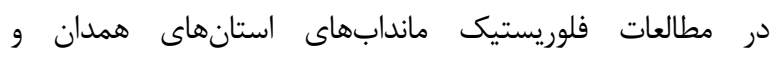

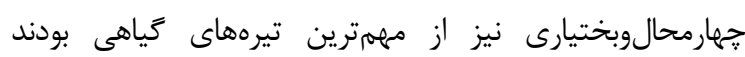
.(Iranmanesh et al., 2017; Safikhani et al., 2018)

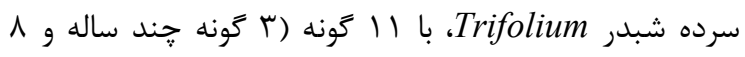

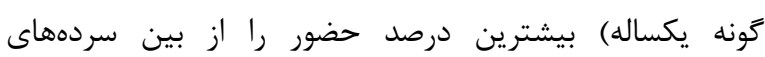

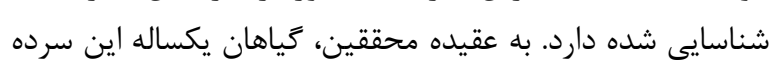

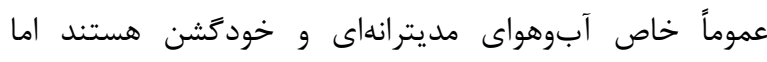

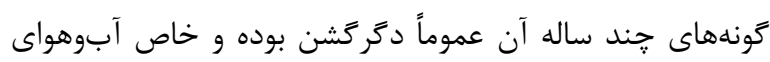
معينى نيستند (Taylor, 1980). بر اساس نتايج حاصل از طيف زيستى عناصر كياهى منطقه

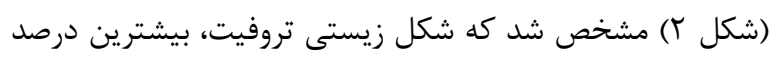

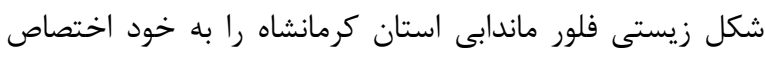

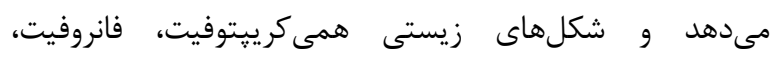

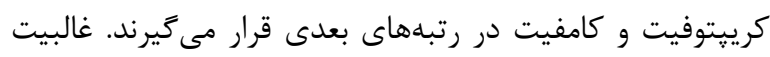

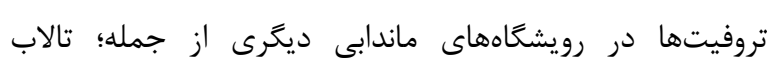
كانىبرزان هم كزارش شده است (Masoomi et al., 2019)

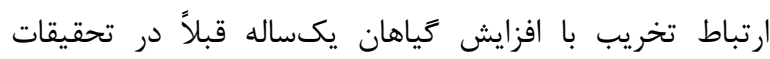

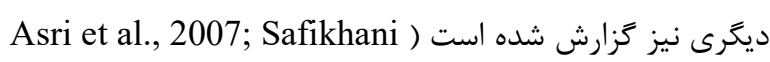




\section{REFERENCES}

APG IV. 2016. An update of the angiosperm phylogeny group classification for the orders and families of flowering plants: APG IV. Botanical Journal of the Linnean Society 181: 1-20.

Archibold, O.W. 1995. Ecology of world vegetation. Chapman and Hall Inc., London. 509 pp.

Assadi, M. 2019. Flora of Iran. Iran Nature 4: 29-41.

Asri, Y. \& Eftekhari, T. 2002. Flora and vegetation of Siah-Keshim lagoon. Journal of Environmental Studies 28: 1-19. (in Persian).

Asri, Y. \& Moradi, A. 2004. Floristic study and biological features of plants in Amirkelayeh lagoon, Iran. Journal of Agricultural Science and Natural Resources 11: 171-179 (In Persian).

Asri, Y., Sharifnia, F. \& Gholami-Terogeni, T. 2007. Plant association in Miankaleh biosphere reserve, Mazandaran Province (N. Iran). Rostaniha 8: 1-16 (In Persian).

Assadi, M. et al. (eds.) 1988-2021. Flora of Iran. vols. 1151. Research Institute of Forests and Rangelands Publication, Tehran (In Persian).

Davis, P.H. 1965-1985. Flora of Turkey and East Aegean Islands, vols. 1-10. Edinburgh University Press. Edinburgh.

Den Hartog, C. \& Segal, S. 1964. A new classification of the water plant communities. Acta Botanical Netherlands, 13: 367-393.

Den Hartog, C. \& van der Velde, G. 1988. Structural aspects of aquatic plant communities. In: Handbook of vegetation science, Symones, J.J. (eds.), vol. 5: Vegetation of inland water. Dr. W. Junk Publishers, Dordrecht: 113-153.

Dinarvand, M. \& Asadi, M. 2011. A review on the submerged and floating plant families in the Khuzestan wetlands, Journal of Wetland 2: 87-94. (in Persian).

Dolatkhahi, M., Asri, Y. \& Dolatkhahi, A. 2011. Floristic study of Arjan-Parishan protected area in Fars province, Taxonomy and Biosystematics 3: 3146. (in Persian).

Galatowitsch, S.M., Whited, D.C., Lehtinen, R. Husveth, J. \& Schik, K. 2000. The vegetation of wet meadows in relation to their land-use, Environmental Monitoring and Assessment, 60: 121-141.

Ghahremaninejad, F. \& Agheli, S. 2009. Floristic study of Kiasar National Park, Iran. Taxonomy and Biosystematics 1: 47-62. (In Persian).

Hogland, B. W. 2002. A classification and analysis of emergent wetland vegetation in western Oklahoma, Proceding Oklaham Academy of Science 82: 5-14.

Hutchinson, G.E. 1975. A treatise on limnology, vol. 3: Limnological botany. John Wiley \& Sons Inc., New York. $645 \mathrm{pp}$.

IPNI. The International Plant Names Index. Retrieved from http://www.ipni.org.on:3 December 2020.

Iranmanesh, Y., Jalili, A., Shirmardi, H. \& Jahanbazi, G.H. 2017. Flora, life form and chorology of plants in the important wetlands of Chaharmahal and Bakhtiari province, Taxonomy and Biosystematics 9: 83-104 (In Persian).

$$
\begin{aligned}
& \text { و سراب ياورى و گونه تيزك Najas marina در سراب روانسر و }
\end{aligned}
$$

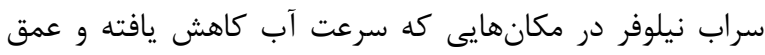

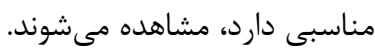

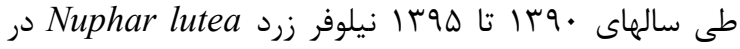

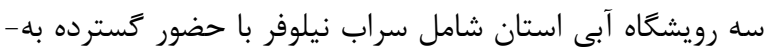

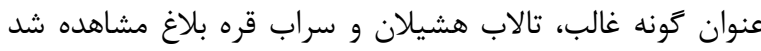

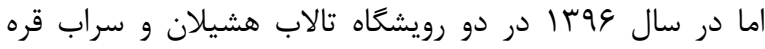

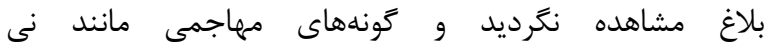
كنند (Khanhasani et al., 2018).

اكوسيستمهاى آبى نسبت به اكوسيستمهاى خشكى به دليل

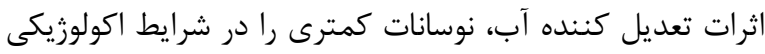

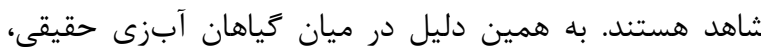

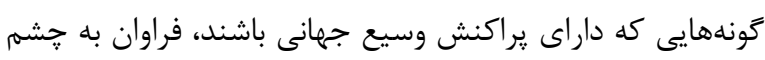

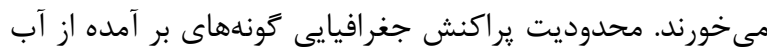

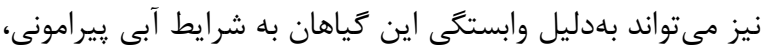

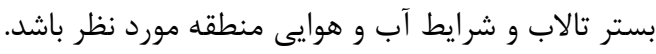

$$
\text { سياسگزارى }
$$

مقالة حاضر بخشى از نتايج يروزءٔ تحقيقاتى ملى بررسى شرايط

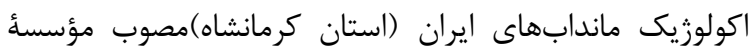

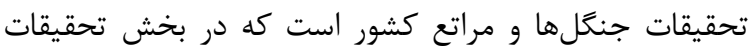

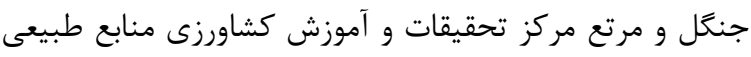

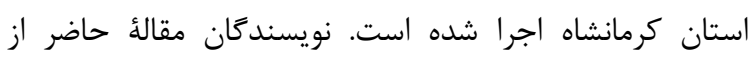

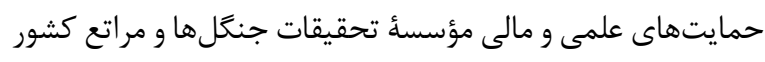

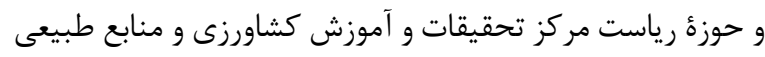

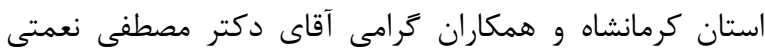

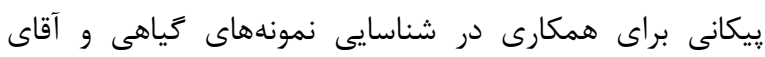

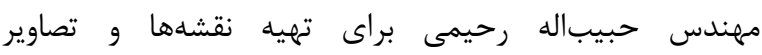
سياسگزارى مىنمايند. 
Jalilian, N., Nemati Paykani, M. \& Jamzad, Z. 2017. Identification of plant speciemens in herbarium of Kermanshah province. Research Institute of Forest and Rangelands. Agricultural Research, Education \& Extension Organization. 98 pp.

Khanhasani, M., Khodakarami, Y., Jalilian, N. \& Jalili, A. 2018. The habitat of Nuphar lutea in Kermanshah province. Iran Nature 3: 86-93.

Klimes, L. 2003. Life-forms and clonality of vascular plants along an altitudinal gradient in Eadakh (NW Himalayas). Journal of Basic and Applied Ecology 4: 317-328.

Lancer, L. \& Krake, K. 2002. Aquatic weeds and their management. Interntional Commission on Irrigation and Drainage: 1-65.

Mansouri N., Khorasani N., Karbasi A.R., Riazi B. \& Panahandeh M. 2013. Assesing human risk of contaminants in Anzali wetland fishes. International Journal of Application or Innovation in Engineering \& Management 2: 119-126.

Masoomi, A. Ghahremaninejad, F. \& Abbaspour, N. 2019. Floristic study of Kanibarazan wetland. Journal of Plant Research 32: 497-509.

Mesdaghi, M. 2001. Vegetation description and analysis. Jahad-e-Daneshgahi Press. 287 pp. (In Persian).

Mobayen, S. 1980-1996. Flora of Iran. vols. 1-4. Tehran University Press, Tehran, Iran (In Persian).

Mozaffarian, V. 1998. A dictionary of Iranian plant names. Farhang Moaser Publication, Tehran (In Persian).

Mozaffarian, V. 2005. Plant classification. Vols. 1-2. Amir kabir Publications, Tehran. (In Persian).

Murphy, K.J. 1988. Aquatic weed problems and their management, a review. The worldwide scale of the aquatic weed problem. Crop Protection 7: 232-234.

Panahy Mirzahasnlou, J., Nejadsattari, T., Ramezanpour, Z., Imanpour Namin, J. \& Asri, Y. 2020. Identification of filamentous algae of the Balikhli River in Ardabil province and recording four new species for algal flora of Iran. Nova Biologica Reperta 7: 331-345. (In Persian).

Petragia, A. \& M. Tomaselli, 2003. Ecological profiles of wetland plant species in the northen Apennines (N. Italy). Journal of Limnology 62: 71-78.
Pieterse, A.H. \& Murphy, K.J. (eds.) 1993. Aquatic Weeds. The ecology and management of nuisance aquatic vegetation. Oxford science publications. $593 \mathrm{pp}$.

Raunkiaer, C. 1934. The life forms of plants and statistical plant geography. Clarendon Press, Oxford. $132 \mathrm{pp}$.

Ravanbakhsh, M., Ejtehadi, H., Pourbabaei, H. \& Ghoreshi-al-Hoseini, J. 2007. Investigation on plants species diversity of Gisoum Talesh reserve forest, Guilan province, Iran. Iranian Journal of Biology 20: 218-229.

Rechinger, K.H. (ed.). 1963-2015. Flora Iranica. 1-174: Akademische Druck- u. Verlagsanstalt, Graz; 175: Akademische Verlagsgesellschaft, Salzburg; 176-181: Naturhistorisches Museum, Wien.

Safikhani, K., Jalili, A. \& Jamzad, Z. 2018. Wetlands flora of Hamedan province (Iran). Taxonomy and Biosystematics 37: 3-46

Sharifi, M., Rezaie Chamany, F., Hosseini, M. \& Raji, Gh. 2004. Stratographical studies in Hashillan wetland: Introducting a patterned mire in western Iran. Journal of Environmental Studies 30: 99-107. (In Persian).

Sharifnia, F., Asri, Y. \& Gholami Terojeni, T. 2007. Plant diversity in Miankaleh Biosphere Reserve (Mazandaran province) in north of Iran. Pakistan Journal of Biological Science 10: 1723-1727.

Tabad, M. A. \& Jalilian, N. 2015. Ethnobotanical study of medicinal plants in Zarivar Region (Marivan), Iran. Journal of Medicinal Plants 2: 55-75. (In Persian).

Taylor, N.L., Quarles, R.F. \& Anderson, M.K. 1980. Methods of overcoming interspecific barriers in Trifolium. Euphytica 29: 441-450

Thakhtajan, A. 1986. Floristic regions of the world. University of California Press, LTD. 552 pp.

Townsend, C.C. \& Guest, E. 1966-1985. Flora of Iraq. vols. 1-9. Ministry of Agriculture and Agrarian Reform, Baghdad.

Zohary, M. 1973. Geobotanical foundations of the Middle East. vol. 2. Gustav Fischer Verlag, Stuttgart. Amesterdam. 738 pp.

How to cite this article:

Khanhasani, M., Jalili, A., Khodakarami, Y. \& Jalilian, N. 2021. Wetlands flora of Kermanshah Province, Iran. Nova Biologica Reperta 8: 154-172. (In Persian).

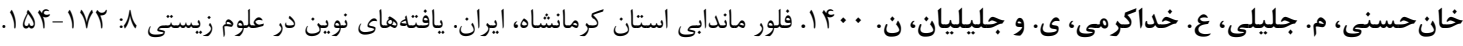

